\title{
Conceptual Design of a Massaging Device to Mitigate Exercise Associated Calf Muscle Cramps
}

\author{
Diana Starovoytova \\ School of Engineering, Moi University P. O. Box 3900, Eldoret, Kenya
}

\begin{abstract}
.
Exercise-associated muscle-cramping (EAMC) is a-common-condition, experienced by recreational and competitive-athletes, which can potentially-endanger their-health, as-well-as professional-career. This paper reports the-synopsis of a-conceptual-design, simulation, and analysis of a-massaging-device to-mitigate paraphysiologic-EAMC, in-the-calf-area. Document-analysis was utilized as one of the-study-instruments (including published-research on the-concepts of cramps and their-treatments; selected-relevant Internationalpatents; the-use of anthropometric-data in product-design; prior-art on massaging-devices, and selected-devices, currently available at the-market, with their-respective-limitations). The-study applied fundamental-Engineeringprinciples of product design, and was-carried-out in-compliance with ISO7250: 1996 (Basic-human-bodymeasurements for technological-design). The-best-ranked-design (out of the 3 design-alternatives, made) was chosen, via Engineering-Design Weighted-Decision-Matrix, and confirmed by the 'Drop and Re-vote' (D \& R) method. 2D-drawings, of the-best-design-alternative, were created by computer-aided-design (CAD) AutoCADsoftware, while $50^{\text {th }}$ percentile, adult-male was selected, as a design-target. Relevant-leg and hand-dimensions (one-dimensional measurements), were obtained from published-anthropometric-data-tables. Simulation of StressAnalysis/Single-Point Static-Analysis (to-detect and eliminate rigid-body-modes; and separate stresses across contact-surfaces) was done by Autodesk Inventor-Version: 2016 (Build 200138000, 138). Conceptual-design of the-massaging-device was optimized according-to results of simulations, calculations, and fundamental engineering-product design principles. The-study also revealed that the-patho-physiology, causing EAMC, is most-likely multi factorial and complex. Overall, the-results of this-concise-study are rather-positive, providing agood starting-point for advanced-exploration on the-same. Further-improvements and trials, however, are necessary. The-study, hence, recommended: (i) Further-studies, to-optimize the-dimensions of the-device, toaccommodate different-shapes of calf-muscles; (ii) More-advanced-methods, such-as PuCC; AHP, and TRIZ should be considered in-selection of the-best-design-alternative; (iii) Comprehensive-materials-selection should be detailed via Ashby-charts; (iv) To-carry-out a-detail-design; (v) To-fabricate a-prototype; (vi) To-conduct additional-tests (e.g., FEA/FEM) and explorative-use-ability-trials, in-collaboration-with the-department of Medical-Engineering, School of Medicine, MU; and (vii) To-analyze the-marketing-aspect of the-final-device. The-device is potentially-beneficial to sports-health-care-providers, coaches, and athletes; moreover, it could be included into-First-Aid Sport-kit (subject-to satisfactory-trails).
\end{abstract}

Keywords: EAMC, spasm, athlete, sports, theories.

DOI: $10.7176 /$ ISDE/10-2-01

\section{Introduction.}

1.1. Spasms, Cramps, and their-manifestations and effects.

A-muscle-spasm is an-involuntary-spasmodic-contraction, occurring suddenly (with no warning), of a-skeletalmuscle, muscle-part, or several-muscles, which are usually-acting-together (Kargus, 2009). A-sustained-musclespasm is referred-to as a-muscle-cramp. Cramps are affiliated-to several-muscles, but usually-occur to the-muscles of the-calf, quadriceps, and hamstrings (Jahic \& Begic, 2018; BMJ, 2014; Young, 2006). According-to Miller \& Layzer (2005), cramps usually-occur in one-muscle, or part of a-muscle, at a-time.

Muscle-spasm can easily-bring even highly-fit-athlete to their-knees, especially if the-muscle-spasm or cramp, occurs during the-active-state (e.g., while-running or performing other-physical activities).These-muscle-spasms, occurring during such-activities are known as Exercise-Associated Muscle-Cramps (EAMC), which is the-subject of this-study.

Schwellnus and his-colleagues provided a-definition of EAMC (Schwellnus et al., 1997), as: "Skeletal muscle cramps that occur during, or shortly-following exercise, in healthy individuals, with no underlying metabolic, neurological, or endocrine pathology". This-definition is adopted by the-current-study.

EAMC leads-to pain and muscular-skeletal-dysfunction that could-induce a-decrease in-performance (Braulick et al., 2013), and could also-lead-to muscle-damage (Edouard, 2014). Clinically, EAMC may-be recognized by acute-pain, stiffness, visible-bulging or knotting of the-affected-muscle, palpable-contraction, and possible-soreness, that can last from few-minutes to several-days (Maquirriain \& Merello, 2007; Miller \& Layzer, 2005). While EAMC can-be-isolated, athletes often-complain of EAMC-symptoms up-to 8 hours after-exercise. This post-exercise-period of increased-susceptibility to EAMC has been termed the cramp- prone-state (Miller \& Knight, 2007). 
Although some-EAMC do manifest only in-mild-discomfort and do not appear to-affect athletic performance (Schwellnus et al., 2007; Maughan, 1986), other-times, EAMC are extremely-painful and can be completelydebilitating (Miller et al., 2010; Brubaker et al., 1985; Moss, 1923), leading-to muscle-injury, and temporarilyloss of mobility, and, hence, can potentially-damage, or even, ruin the-carrier of a-sport man or a-woman.

\subsection{Statistics/prevalence of EAMC.}

EAMC is common-among-athletes, participating in-long-distance-endurance-events, such-as tri-athlon and marathon, or ultra-marathon distance-running, and it-is documented in many-other-sports, including: basketball, soccer, American-football, tennis, cricket, and cycling (Schwellnus et al., 2008; Kantarowski et al., 1990). Theprevalence of EAMC has been reported for: tri-athletes at 67\% (Kantarowski et al., 1990); marathon-runners between 30\% and 50\% (Kantarowski et al., 1990); rugby-players - 52\% (Summers et al., 2013; Schwellnus et al., 2008); and cyclists - 60\% (Schwellnus et al., 2008).

EAMC-susceptibility varies-widely, among individuals; some routinely-develop EAMC, while others, despite-being similarly-matched for conditioning, duration, and intensity, demonstrate cramp-resistance (Shang et al., 2011; Schwellnus et al., 2011). In-the-same-spirit, Miller \& Knight (2009) reported that cramp-susceptibility is correlated-with an-individual-cramp threshold-frequency (CTF), defined as the- minimum electrical-stimulation, required to-evoke a-muscle-cramp.

\subsection{Classification.}

Controversy persists regarding the-classification of muscular-cramps. Parisi et al. (2003) described a-patho genesis-based-classification for this-muscular-condition, establishing three-different-types of cramps: (i) paraphysiologic; (ii) idiopathic; and (iii) symptomatic.

Paraphysiologic-cramps develop in-healthy-people and are linked-to certain-circumstances and conditions, such-as exercise or pregnancy. In-idiopathic-cramps, the-muscular-problem is the-main symptom of a-generaldisease; these can-be sporadic, are sometimes inherited, and usually are not associated with cognitive, pyramidal, cerebellar, or sensory-abnormalities. A-central, neuronal-origin, at the moto-neuron-level has generally been hypothesized for these-cases. Symptomatic-cramps are manifestations of an-underlying-disease. The-scope of this-study is limited to paraphysiologic-cramps.

Besides, there are two-distinct and dissimilar general-categories of EAMCs (when there is no other underlying-pathology or abnormal-condition-present): (i) First, skeletal-muscle overload and fatigue, from overuse or insufficient-conditioning can prompt muscle-cramping-locally in the-overworked muscle-fibers (Jung et al., 2005; Bentley, 1996); and (ii) Large-sweat-losses commonly-occurred in exercising-athletes (Stofan et al., 2005; Bergeron 2003, 1996). Extensive-sweating and a-consequent significant-whole-body exchangeable-sodiumdeficit can lead-to more-widespread muscle-cramping, even when there is minimal or no muscle-overload and fatigue (Stofan et al., 2005; Bergeron, 2003, 1996). This-latter-type of muscle cramping has-been-referred-to as exertional-heat-cramps (Weller et al., 1998); such-term causes some confusion (as cramps often do occur in-coolenvironments, and even indoors, although considerable sweating still is present).

The-information, presented here supports the-contention that there are two-primary-categories of EAMC:

(1) Those related-to muscle-overload and fatigue (Buono et al., 2007; Cleary et al., 2007; Schwellnus, 2007, 1997); and

(2) Those skeletal-muscle-cramps, associated-with a sweat-induced-sodium deficit (exertional heat-cramps).

The-current-study assumes that both-courses could be contributing to EAMC.

Lastly, though controversial, an-important-differentiation, in-determining the-cause of EAMC, may-be thenumber and location of muscles, affected. EAMC typically-occur in-single, multi-joint-muscles (e.g., triceps surae, quadriceps, hamstrings), when contracting in a-shortened-state (Schwellnus et al., 2007), whereas generalizedEAMC occur in-multiple, usually-bilateral-muscles.

Calf-muscle (the-focus of this-study) is a-bilateral-muscle. Figure 1 shows the-anatomical- position and depiction of the-calf-muscle, which is the-focus of this-research. 


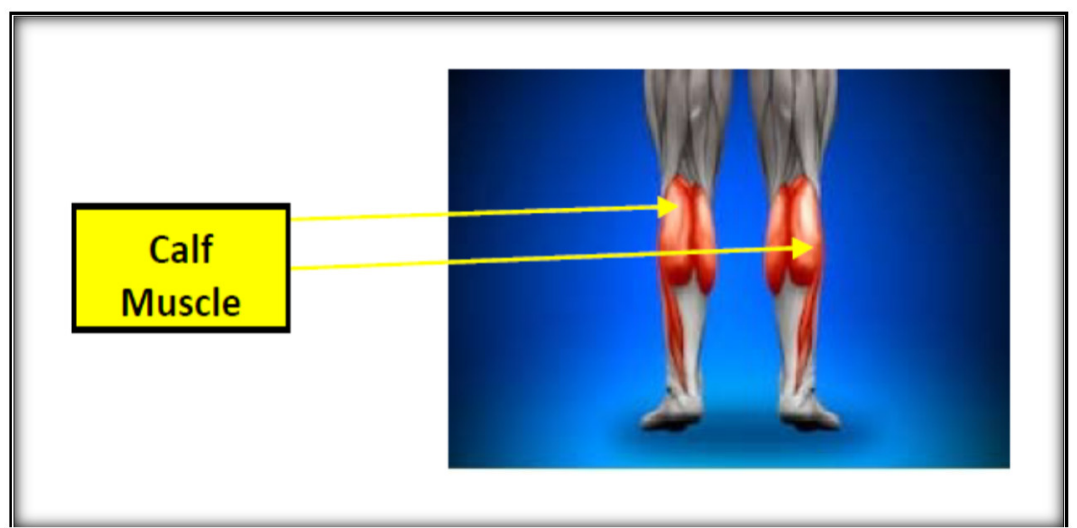

Figure 1: Calf-muscle-position.

\subsection{EAMC: Causes and relevant-theories.}

EAMC was first-described in the-early-1900s in-association-with physical-work, done in-hot-humid environments (see Edsall, 1908; and Talbot, 1935). The-very-first-hypotheses for the-aetiology of EAMC were proposed over 80 years-ago, when the-condition was-thought to-be-related-to abnormal-serum electrolyte-concentrations, dehydration, or environmental-stress (see Talbot, 1935; Ladell, 1949; Schwellnus et al., 1997). A-new-hypothesis, proposed in the-late 1990s, suggested that muscle-fatigue, and therefore altered-neuro-muscular-control, was theprimary-factor, associated-with developing EAMC (Schwellnus et al., 1997). Cramping has-been-reported tooccur most-commonly in the-later-stages of an endurance event, when fatigue would be a-factor (Manjra, 1991). EAMC are more-likely to-occur when the muscle is contracting in an already-shortened-position (Schwellnus et al., 1997; Ruff, 1996). Shortened muscle is more-prone-to cramping, may explain why calf-muscle-cramps are prevalent in-swimmers, because in most-swimming-races a-swimmer must-swim-with pointed-toes, that require the-calf-muscle to remain somewhat-contracted (Schwellnus et al., 2007; Bentley, 1996).

Different-theories for the-aetiology of EAMC are highlighted (see for details Eichner, 2007; Sulzer et al., 2005; Jung et al., 2005; Schwellnus et al., 2004; Bergeron, 2003; Schwellnus et al., 1997; Armstrong \& Maresh, 1993; Hutton \& Nelson, 1986; Maughan, 1986; Nelson \& Hutton, 1986; Ladell, 1949; McCance, 1936 a, b; Talbot, 1935; Derrick, 1934; Oswald, 1925; Edsall, 1908) as-follows:

Serum-electrolyte-theory

This-theory suggests that EAMC is related to the-decreased-concentration of serum-electrolytes (sodium, potassium, magnesium, chloride, and calcium), resulting-from profuse-sweating or overconsumption of water (Sulzer et al., 2005; Schwellnus et al., 2004; Schwellnus et al., 1997; Armstrong \& Maresh, 1993; Maughan, 1986; Ladell, 1949; McCance, 1936 a, b; Derrick, 1934; Oswald, 1925; and Edsall, 1908). On-the-other-hand, severalstudies have shown no relationship between serum-electrolyte-abnormalities and EAMC in marathon-runners or tri-athletes (see Drew, 2006; Sulzer et al., 2005; Schwellnus et al., 2004; and Maughan, 1986). The-findings have led-to suggestions that increased-sweat-concentration ('salty- sweating') resulting-in sodium-depletion, rather than changes in-serum-electrolyte-concentrations, is the mechanism for EAMC (Eichner, 2007; Bergeron, 2003). Besides, exercise-induced-sweating causes fluid to shift, from interstitium, to intravascular-space (Bergeron, 2008), which alters excitability on selected nerves (Miller et al., 2010). However, according-to Armstrong \& Cross (2013), the-pathophysiological basis for this-proposal is not clear and has not been formally-outlined.

Dehydration theory

According to the-dehydration-theory, excessive-sweating is the-primary-cause of EAMC (Braulick et al., 2013; Bergeron, 2008; Jung et al., 2005; Stone et al, 2003; Schwellnus et al., 1997). This-theory is propagated, becauseof the-association of heat-illness with cramps. However, Armstrong \& Cross (2013) pointed-out, that thedehydration-theory is based-on anecdotal-observations, with no actual-measures of hydration-status reported. In the-more-recent-studies by Drew (2006); and Sulzer et al. (2005), in-which calculated-body-weight-changes and volume of blood or plasma, were used as-indicators of hydration status, the-hypothesis of a-direct-relationship, between dehydration and muscle-cramping, was not supported.

Environmental theory

The-environmental-theory suggests that exercising in hot-conditions and the-subsequent-electrolyte-loss and dehydration, results in-EAMC (Bergeron, 2003; Schwellnus et al., 1997; Armstrong \& Maresh, 1993). However, Armstrong \& Cross (2013), have argued that EAMC is not directly-related to an-increased core temperature. Atrest, however, passive-heating does not result in skeletal-muscle-cramping and cooling does not relieve it, so it-is unlikely that exercising in hot-conditions causes secondary physiological changes, which can cause EAMC.

Altered neuromuscular control theory

During sports-competition, training, and a-variety of other-intense-physical-activities, repeated or extended- 
loading, on selected-muscles can lead-to localized-muscle-fatigue. The-altered-neuro-muscular control-theory suggests that muscle-fatigue disrupts the-normal-functioning of peripheral-muscle-receptors, causing an-increase in excitatory afferent-activity, within-the-muscle-spindle, and a-decrease in-inhibitory afferent-activity, within the-Golgi-tendon-organ, both of which then lead-to an-increase in-alpha motor neuron-discharge to the-musclefibers, producing a localized-muscle-cramp (Miller, 2015; Schwellnus et al., 1997; Ruff, 1996).

In-simple-terms, according to this-theory, EAMC is a-result of a-muscle-fatigue (Schwellnus, 2009; Bentley, 1996). Besides, according-to O'Connell et al, (2013); and Schwellnus (2009), primary-factors, in- thedevelopment of EAMC, are: "increased exercise intensity or duration, development of muscle fatigue, muscle contraction in a shortened position, and possible tissue damage', Figure 2 shows the-system of factors, associated with EAMC, according to this-theory.

The-Altered-neuromuscular-control-theory seems to-be the-most scientifically-acceptable-theory, suggesting that EAMC are caused by an-imbalance, between increased-afferent-activity (e.g., muscle spindle), and decreasedinhibitory afferent-activity (e.g., Golgi-tendon-organs), which leads-to increased motor neuron-activity and muscle-cramping, especially with muscle-contraction in a-shortened-position. This is also supported by alaboratory-based exercise-protocol, specifically-designed to-cause premature- fatigue, of the-calf-muscles, has been shown to-result in a-high-incidence of muscle-cramping, during exercise (Jung et al., 2005).

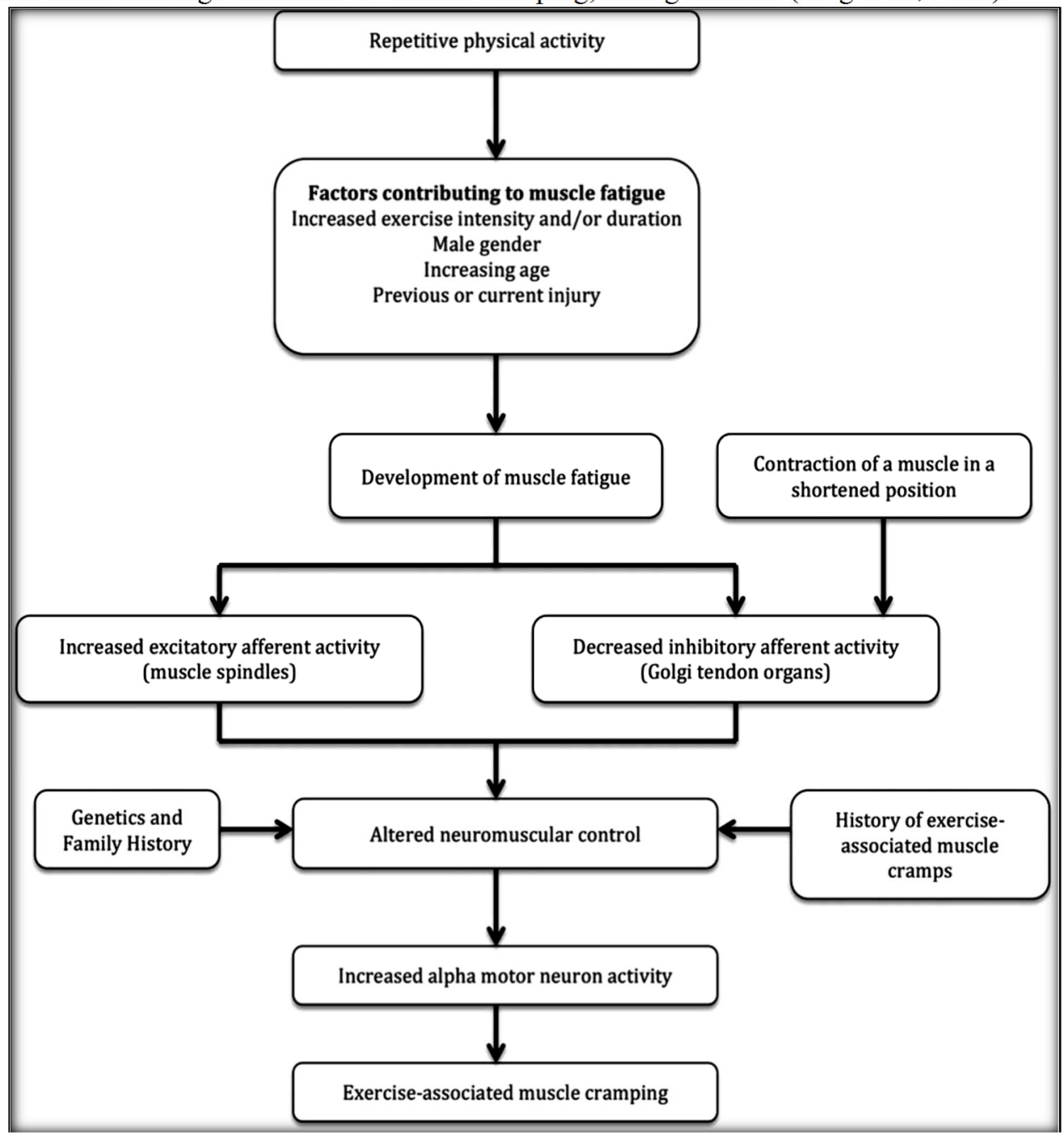

Figure 2: Factors associated with EAMC (Miller \& Layzer, 2005).

Among other-theories, that have been-proposed for the-etiology of EAMC, are an-inadequate-intake of carbohydrate, glycogen-depletion, poor-biomechanics or running-gait, hilly-terrain, and lack of adequate massage, before and during-a-game (Schwellnus et al., 2008). Cramp-discharges may-also be attributed to the-fact that terminal-branches of motor-axons are exposed-to increased-concentrations of excitatory extracellular-substances, such-as acetylcholine or electrolytes (i.e., sodium and potassium) (Ruff, 1996; Layzer, 1994; Sjogaard et al., 1985).

The-electrolyte-imbalance-and-dehydration-theory suggests that EAMC is related to the-decreased concentration of serum-electrolytes, particularly sodium and chloride, resulting-from excessive-sweating or overconsumption of water (Schwellnus et al., 1997; Armstrong \& Maresh, 1993; Ladell \& Camb, 1949). On-the-other- 
hand, according-to Armstrong \& Cross (2013):"muscle fatigue is now acknowledged as the principal predisposing factor in the development of EAMC". This-study, however, supported Miller and his colleagues, who pointed-out, that (Miller et al., 2010):

Because EAMC occur in a variety of situations, environmental conditions, and populations, it is unlikely that a single factor (e.g., dehydration, electrolyte imbalance, or neuromuscular factors) is responsible for causing them directly. It is more likely that EAMC are due to a combination of factors that simultaneously occur under specific physiological circumstances in each athlete.

Muscle-cramping can-also-occur as-a-symptom for a-variety of medical-conditions, including: Hypothyroidism, vascular-disorders, metabolic-myopathy (caused by glucose-metabolism-defects), radiculoneuropathy, serum-deficit of magnesium, Parkinson's disease, diabetes mellitus, peripheral-neuropathy, electrolyte-disorders, venous-insufficiency, or chronic-obstructive arterial-disease of the-lower-limb (Parisi et al., 2003; Tarnopolsky, 2002). Muscle-cramps are also part of certain-conditions such-as: Compression of nerve; kidney disorder, hypo-glycemia; and anemia (Qiu \& Kang, 2017).

Cramps also may-occur as a-side-effect of certain-toxic and pharmacological-agents/drugs (e.g., lipidlowering-agents/ diuretics, blockers, anti-hyper-tensives, agonists, insulin, oral-contraceptives, and alcohol) (Qiu \& Kang, 2017; Maquirriain, 2007).

Moreover, according-to Armstrong \& Cross (2013); Schwellnus (2007); and Manjra et al. (1996), potentialcontributing-factors in these-theories include: genetic-predisposition and family-history; lack of adequate-massage, before and during a-game; insufficient-carbohydrate loading or carbohydrate inadequacy, during-exercise; groundconditions (ground 'hardness'); and poor-biomechanics or poor-running-gait.

\subsection{EAMC: Treatment-approaches, including preventive-measures and therapeutic-massage.}

Schwellnus (2009) pointed-out, that severe-EAMC, during-sporting-events, requires urgent-medical attention. Effective-immediate-treatment is to-increase inhibitory-input to the-muscle, either by stretching, or by electricalstimulation of the-tendon. Immediate-treatment of the-acutely-cramping-athlete requires passive-stretching of theaffected-muscle-groups, and maintaining the-stretched-position, until fasciculation ceases. Other-measures include cooling the-skin-temperature, when excess-heat is an-issue, as-well-as oral- hydration. Drug-therapy (e.g., diazepam, magnesium, quinine, calcium) however, is not recommended.

When the-urine is dark or scarce, during the-first-hours, fluid-replacement, along-with further-clinical and laboratory-study is recommended (Maquirriain, 2007; Sulzer et al., 2005). Besides, Miller (2014) also recommended: thermotherapy, cryotherapy, sports-drinks, salt and electrolytes, pickle-juice, intravenous infusion, and trans-cutaneous-electric nerve-stimulation. Recently, an-effort has-been-devoted to-evaluate a-method of using food-extracts like peppers, ginger, mustard, and cinnamon to-resolve EAMC.

Preventive-measures include reducing-training and competition-intensity and duration (e.g., by lowering overall-exercise-intensity and altering the-load on the-distressed-muscle(s)), as-well-as improving conditioning, and range of motion, through appropriate and regular-individualized-progressive fitness and stretching-programs. Adjustments to equipment-configuration and selection (e.g., bicycle-seat and handle position, shoes), biomechanics, and relaxation-techniques may also-help to-avert, or delay, fatigue-induced muscle-cramping (Roeleveld et al., 2000; Bentley, 1996; Riley \& Antony, 1995). In addition, Bergeron (2008) pointed-out, in hisstudy, that fluid-replacement $(89.8 \%)$, proper-nutrition $(72.8 \%)$, electrolyte replacement $(70.3 \%)$, and properstretching $(55.8 \%)$ were perceived as extremely-successful prevention strategies.

On-the-other-hand, the-athlete, presenting-with severe or generalized-cramps in-muscles, not subjected to exercise, or with localized-cramping together-with-confusion, altered-state of consciousness, or other-signs of central-nervous-system-involvement, should receive emergency-medical-attention. These patients are likelysuffer-from a-systemic-disease, such-as a-metabolic-disorder (Maquirriain, 2007; Tarnopolsky, 2002). Suchpatients require immediate-hospitalization, to-rule-out volume-depletion, electrolyte-imbalance, acute-renalfailure, intracranial-disorders, or other-systemic-conditions (Maquirriain, 2007; Coppin et al., 2005).

Massage-therapy as therapeutic-treatment of EAMC is the-primary-focus of this-study. Massage therapy is designed to-stretch, calm, revitalize, and loosen the-affected-muscles, improve blood flow, facilitate the-removal of metabolic-wastes, resulting-from exercise, or inactivity, and increase the-flow of oxygen and nutrients to thecells. In-addition, massage stimulates the-release of endorphins (the-body's natural-painkiller) into the-brain and nervous-system (Zainuddin et al., 2005; Robertson, 2004; Hilbert et al., 2003; Hemmings et al., 2000).

Massage, and associated-soft-tissue-treatment, is an-important-component of the-training-process for manyelite-athletes, as muscle-tightness interferes with the-nerve-feedback-mechanisms, which ensure efficient and smooth-control of movement, so necessary in-competitive-sport. Indeed, according-to Bergeron (2008) and Jönhagen et al. (2004), the-request for sports-massage, among competitive-athletes, has seemed to-increase during the-past-years. Many-top-level-athletes consider this-treatment as-enhancing their-recovery, after training and competitions, as-protection from overuse-injuries, and as reducing the-risk of delayed-onset-muscle-soreness (DOMS) (see Thomson et al., 2015). DOMS normally follows unaccustomed-eccentric-exercise, and the-peak of 
muscle-soreness is seen 24 to 72 hours (Stone et al., 2003; Friden \& Lieber, 2001; Byrne et al., 2001; Angus, 2001; Armstrong et al., 1991), after-exercise.

In-addition, it has-been-proposed that the-mechanical-pressure, during-massage, alters neural excitability, and these-neural-changes may-reduce the-potential for cramping (Nelson \& Churilla, 2016; Behm et al., 2013; Lee, 2009). Sefton et al. (2012) discovered a-reduction in the-Hoffman (H)-reflex, which was-used to-measure the-excitability of the-motor-neuron-pool, in-study-participants, who received a 1-hour full-body-massage. Analogous, Behm et al. (2013) found that massage decreased spinal-reflex excitability, with significant-reductions, in-subjects, who received 30 seconds of a percussive-massage stroke. They, however, pointed-out, that furtherinvestigation is warranted to-determine whether treatment variables, such-as the-relative-timing of massage, depths of pressure, speed of stroke, and type of massage stroke, influence EAMC, without negatively-impactingperformance.

Numerous-studies have-been-conducted, regarding the-capabilities of effleurage-application, on the- calfpart, and it was-found that there are essentially-perceived-effect of massage on the-circulation, where superficialeffleurage should be centripetal (Halperin et al., 2014; Miller et al., 2010; Bergeron, 2008; Callaghan, 1993). Moreover, in-accordance-with the-muscle-spindle/GTO-imbalance-Theory, stretching, and frictional-icingmassage, of the-affected-muscle-groups, may-help to-relieve painful-muscle-spasm, in acute-cases (Maquirriain, 2007), and hence has been frequently-recommended in-the-literature (Miller \& Layzer, 2005; Kenefick et al., 2001; Schwellnus et al., 1997; Bentley, 1996; Bergeron, 1996; Guissard et al., 1988).

\subsection{Research-purpose.}

EAMC can be severe, reguiring immidiate-medical-attention. According-to Venable (2009), the-most effectiveway of muscle-spasm-relieve, is by the-use of drugs, which reduce the-firing-effect of the motor neurons, or act to the-central-nervous-system, to-reduce pain-sensitivity. One of these-drugs is Quinine-Sulfate; however this-drug causes the-feeling of nausea, dizziness, partial-blindness, and even death; these-side-effects being greater-than theadvantages, therefore, this-drug is rarely-used (Timothy, 2005). In other-severe-situations, the-patient is advised to-undergo a-surgery, known as-orthopedic-surgery, to-correct the-muscle-situation.

On-the-other-hand, massaging-devises are relatively-effective and harmless, in-mitigating EAMC. Preliminary-assessment showed, that the-majority of massaging-devices rely on external-power (such-as batteries, electricity), this power-requirement, however, could be a-big-disadvantage, when such-sources do fail. Forexample, athletes may experience EAMC, at the-middle of the-field, where there is no electric- source, which endangers their-mobility and even their-career.

In-addition, the-author was not able to-trace freely-available-published-literature on the-design of massagingdevices; with-exception of one-article, by Kamat et al. (2017), who described a-design a-manual calf-massager for prolonged-standing-workers. Hence, there is a-gap, to-be-filled.

Considering the-above-limitations, the-aim of the-current-research was to-design a-manual, simple, costeffective massaging-device, that can-be-used to-manage EAMC, in the-field.

\section{Materials and Methods.}

\subsection{Concepts of Engineering-design and Conceptual-design.}

Design can-be-described as a-set of decisions, taken to-solve a-particular-set of product-requirements. Design is part of a-human problem-solving-activity, beginning with a-perception of a-gap in a-user- experience, leading-to a-plan for a-new-artifact, and resulting in the-production of that artifact. Product design is conceiving and giving form to goods and services that address needs (Burdekin, 2007). Within the product-development-process there are several-phases: idea-generation, product-definition (also-called product-planning), conceptual-design, detaildesign, and embodiment-design (Timings, 2000).

The-conceptual-design-phase is the-most-important-phase in concurrent-engineering, after the-project planning-phase or product-definition. Approximately $80 \%$ a-product's life-cycle costs are committed through design-choices, such-as materials and manufacturing-process-selections in this-phase. Conceptual- design comprises concept-definition, exploration, evaluation, and selection (Allen \& Carlson-Skalak, 1998). The-inputs, into-the-design-process, are shown in-Figure 3. 


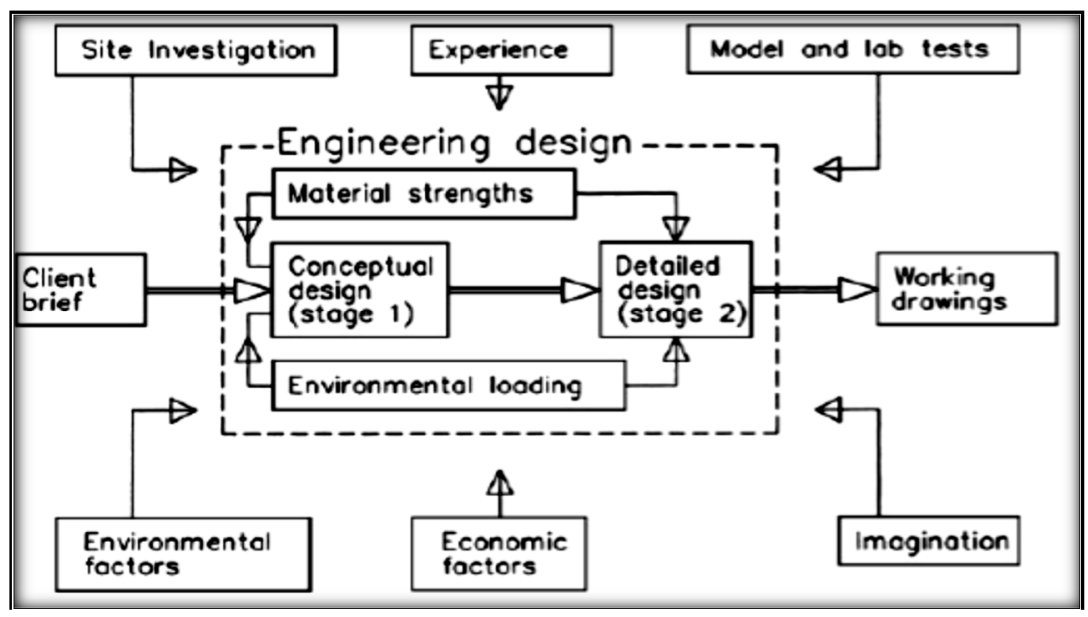

Figure 3: Inputs into the-design-process (Arya, 2009).

\subsection{Steps and tools involved in the-current-study.}

This-study was focused on product-design, where several-tools have to-be-applied. Design-tools enable productdesigners, to-structure and formalize parts of their-design-steps (Jangager, 2005). In-particular, this study is basedon the-bottom-up-approach, where the-design starts-with specifying-requirements and capabilities of individualcomponents (see Crespi et al., 2011).

In-particular, to-achieve the-study objectives, the-following-steps were conducted: (1) formulate designproblem with target-specifications; (2) prepare and analyze design-alternatives; (3) conduct design simulation and analysis; and (4) establish optimum-conceptual-design, based on the-analysis of results.

Romer et al. (2001) stated, that traditional-tools, such-as sketches and simple-physical-models are very-useful and cost-efficient, in-generating design-solutions, in early-phase of design-process. Besides, most of the-times (this-study included) design-problems, are open-ended; they do not have a-unique, or the only-one correct-solution, though some-solutions will, clearly, be-better, than others. In-this-regard, three design-alternatives, is to-be handsketched.

Product-designers utilize a-wide-variety of design-tools, ranging from sophisticated-computerized information support-systems, such-as CAD-systems, to inexpensive-memory-aids, such-as pencil and paper (Love, 2003). This-study, for-example, used a-pencil and paper, as tools, for free-hand-sketching, of three alternativedesigns; and a-database, as a-tool for information-storage and retrieval. The-design also applied fundamentalEngineering-principles of product-design. Besides, this-study was-carried-out in-compliance with ISO7250: 1996 (Basic-human-body-measurements for technological-design).

Engineering-design can-be-considered as a-complex-process, made of a-series of decisions (i.e., 'either-or') and compromises (a trade-off) (Allen \& Mistree 1997; Rajan 1996). The-existing related literature proved that decision-making-methods could-be very-useful in-engineering-design (Chen et al., 2013; Krishnamurty, 2006). According-to Renzi et al. (2017), who reviewed the state-of-the-art knowledge on decision-making methods: "Adecision generally-implies the-selection of a-proposal, aiming at recognizing the-one, that best-fits with goals, objectives, desires, and values". Renzi et al. (2017) further indicated, that according-to the-nature of thedecisional-problem, proposed (multiple-criteria decisional problems, unstructured/ill-posed-problems, and structured-problems), decision-making-methods for solving engineering-design-problems involve three-maingroups: (i) Multi-Criteria Decision-Making (MCDM) methods (Belton \& Stewart, 2002) (ii) Problem-StructuringMethods (PSMs) (Rosenhead \& Mingers, 2001); and (iii) Decision-making Problem-Solving (DPS) methods (Ernawati, 2015). This-study used a-standard Engineering-Design Weighted-Decision-Matrix (EDWDM), toselect the-best design-alternative.

2D-drawing, of the-best-design-alternative, was created via computer-aided-design (CAD) AutoCADsoftware. Furthermore, identification of specific-anthropometric-dimensions and the-design target-population was identified and specified. These-dimensions were used for the-preliminary-design.

Simulation of Stress-Analysis/Single-Point Static-Analysis (to detect and eliminate rigid-body-modes; and separate stresses across contact-Surfaces) was done by Autodesk-Inventor-Version: 2016 (Build 200138000, 138).

According-to Ashby (2004), first-consideration, in materials selection, is on the-functionality of the material, the-main-goal here is being-able to-produce products that function effectively, safely, at acceptable-cost. Thisstudy adopted the-interaction of function, materials, shape, and manufacturing- processes from Asbhy (1999), and the-interaction of use, function, materials, and shape, from Roozenburg \& Eekels (1995). 


\section{Results and Discussion.}

\subsection{Document Analysis.}

A-number of relevant-International-patents (developed by individuals, as-well-as design-companies) were reviewed; examples included: US 7223251 B1 (2007); US 6027434 (2005); US 6784127 B1 (2004); US 6645089 B2 (2003); US6638184 B2 (2003); US 6499485 B1(2002); US 6241696 B1(2001); US 6210304 B1 (2001); US 6146343A (2000); US 6093159 A (2000); US5868689 A (1999); and D403076 S (1998).

Figure 4 shows selected-examples of most-recent-patents, reviewed.
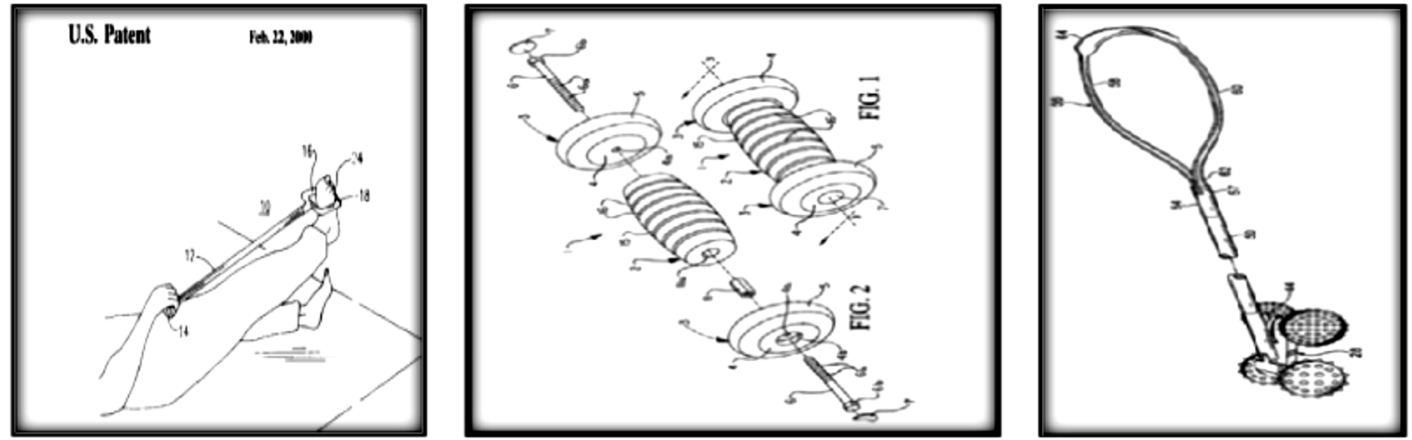

Figure 4: Selected Patents, reviewed.

Key: left - US 6027434 (2010); middle - US 7223251 B1 (2007); and right - US 6027434 (2005).

The-following-limitations were identified in the-specified-patents:

(i) In-the-Patent US 6027434 (2010), the-major-limitation is the-rigidity of the-design, as the-device cannot be used universally (e.g., for athletes of different-hight). Second-limitation is that the-device only utilizes stretching-function; no massaging. Third, the-device tends to-pinch the-sides of the-users-feet, as tension is applied to-pull the-leg. Besides, this-device may only be limited to-handle the-cramps of the quadriceps, and can hardly-be-used for the hamstrings, since the-stretching-direction cannot be changed.

(ii) In-the-Patent US 7223251 B1 (2007), most-people, using rollers to-relieve muscle-spasms agree that they are quite-effective, but it requires technique, especially if the-roller lies on the-ground, as suggested in this-design.

(iii) In-the-Patent US 6027434 (2005), the-spherical-shape of the-roller does not bring-about adequatemassaging-action and it's generally more-difficult to-bring such-balls to-rotate. The-manner, in-which theserollers are attached at the-end of the-handle, is not clear whether massaging of the-leg occurs when the-rollerarrangement is intact, or that they have to-be-detached. Usually, one needs a-closer contact with the-massagingrollers of which this-massaging-system entirely-depends-on the-amount of pressure the-user applies.

The-study also examined selected-examples of available, on the-market, devices. Figure 5 shows someexamples of the available-devices.

Most-of the-available-devices, reviewed, utilize the-principle of electrotherapy, which are powered electrically, used transducers to-produce a-vibration-motion. Some of the-electrotherapy-devices are the FES (Functional-Electrical-Simulation), which mainly-stimulates the-muscles of the-ankle and the-foot, when one is walking (Bailey, 2011). The-FES-pad is attached on the-particular-foot-muscle and triggers it, during-walking. TENS (Trans-cutaneous Electrical-Nerve-stimulation) is a-pad, attached to-the-muscle, and generally affects thepathway of pain to the-brain, hence eases the-pain. TENS-devices, however, could cause some-skin-irritation with use (Bailey, 2011). So-many-devices have-been invented and currently being-sold, however, these-devices are quite-expensive, for any-developing-country, Kenya is not an-exception.
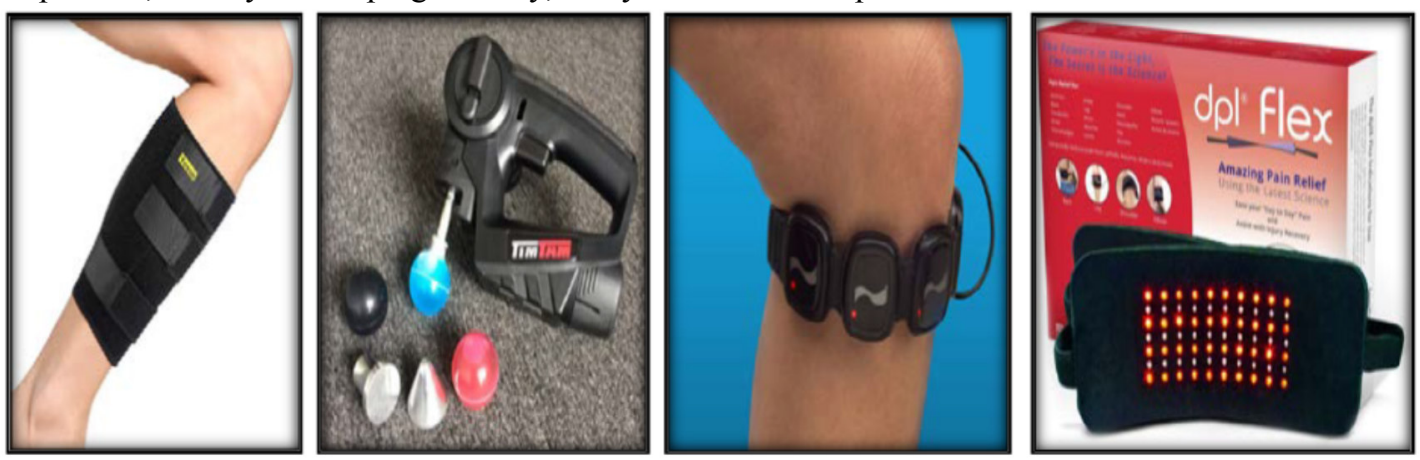

Figure 5: Selected-examples of the available-devices, to relieve EAMC.

Keys (from extreme-left (i) ... to extreme-right (iv)):

(i) - Calf Braces; (ii) - Power massage device;

(iii) - Lumiwave Theraphy Device; and (iv) - Laser pain relief device. 
(i) In-Calf-Braces-device, calf-compression-brace is designed to-support the-calf and shin in-case of a muscle-strain or a-muscle-pull, they are used to-provide-compression to the-affected-calf-area (Mathews, 2016);

(ii) Power-massage-device (by Brick, 2017), has a 12V battery and makes 2000 strokes per-minute and costs $\$ 399$ which is quite-high. Another-limitation is that the-speed of the-device is constant, giving no room for adjusting (Brick, 2017), and again the-noise, it produces, is quite-high, especially when it has to-be-used tomassage areas near the-ear (Matt, 2018);

(iii) Lumitherapy-Device infrared-Light-device uses infrared-light to-reduce muscle-pain, joint-pain and stiffness, with the-light, emitted ensuring proper-blood-circulation and also relieves muscle-cramps. The-device can have 4 pods or 8 pods, going at $\$ 512$ and $\$ 712$ respectively, at the-Amazon. One-user, in their-chart-reviewsite commented that the-device was not powering properly, other-users claim that this- device produces anannoying buzzing-sound; and

(iv) Laser-pain-relief-device consists of a-flex-pad, on-which a 60 LED (Light Emitting Diodes) infrared and red-light, arranged in an-array. The-infrared-light supposes to-stimulate blood-circulation, enables musclerelaxation, and relieve muscle-spasms, pains, aches, sprains, strains, carpal-tunnel Syndrome, and other-physicalailments. Going at \$180.99, this-device can be used for therapeutic purposes, and claimed to-cause faster-healing of tissues. A-disappointed-user, however, explains how the-product stopped working, just after six-months of using it, and the-pad and the-LED separated for other-cases (Grainge, 2016). Another-complains is that the-LEDS are too-bright, and one would-require to-buy safety glasses, while using them.

\subsection{Identification of target-specifications/objectives of the-massaging-device.}

Document-analysis revealed that the-selected-reviewed-devices have a-number of limitations. For-example, some of them: (1) are lacking massaging and stretching capability; (2) cannot be used universally; (3) are bulky and heavy; (5) are expensive to-buy and to-maintain; (6) are not effective in-severe-cases of EAMC; (7) produce extreme-vibrations and make a-buzzing-sound; (8) use power (e.g., electricity; inverter; battery) and use potentially-harmful infrared-light, for operation; and (9) can have side-effects, e.g., skin irritations, and generaldiscomfort, among-others.

The-current-design will focus on addressing the-above-limitations; and therefore, the-device should be: (i) capable of effectively-relieving EAMC, via simultaneous-compressive and massaging-functions; (ii) adjustable, to-carter for several-sizes (e.g., height); (iii) compact, lightweight, foldable, and portable; (iv) reliable (no need for power; manually-driven); (v) cost-efficient (affordable); (vi); durable and made of compatible-materials (nontoxic); (vii) manually-operated and, hence, relatively-quiet; (viii) serviceable (consisting of few-easilyreplaceable-parts); (ix) thermally-comfortable and bio-compatible; and (x) environmentally-friendly (can be easily and economically-recycled).

In-particular, the 3 major-utility-characteristics of the-device are: functional-efficiency, adjustability, and thermal-comfort-ability. It also should-be portable, easy to-store, and to-transport. Bio-compatibility was alsotaken into-consideration as a-constraint; the-device must not irritate the-skin, or result in a-higher surfacetemperature. With proper-material-choice, that incorporates sweat-wicking or a reasonably-high thermalconductivity, the-body-heat can-be-dissipated, easily, to-prevent profuse-sweating and, hence, discomfort.

Besides, a-device usually comprises of various-parts. The-utilitarian or functional-part is the-one that trulyperforms basic-task, which prompts the-execution of the-segment. The-non-functional-part does not have realwork in-segment-presence, but rather it needs to-do-with support, spreads, examination, and aesthetical-worth, and therefore, the-number of non-functional-parts should-be-reduced to-cut the-cost (Juvinall \& Marshek, 2012; Budynas-Nisbet, 2008).

In-summary, the-device should-be: Efficient (relives calf-muscle-cramps); Functional (easily maintained, user-friendly); Pleasant in Appearance (suitable size and shape, attractive-design, good finishing); Durable (not easily-broken, stable, and robust-design, strong sound-structure); and Safe (harmless to the-user, no-side-effects, environmentally-friendly).

To-achieve these-criteria, structurally, all-the-components should: (a) be symmetrical (and have polargeometry-mark), if possible, as this also-helps in-manufacturing; (b) have consistency, in the-dimensions, used for feeding, orientation, and location; (c) have location-points; and (d) be functional, hence, components which are not important/functional should-be-eliminated.

\subsection{Free-hand-sketches of design-alternatives.}

The-study limited to three-design-alternatives, developed, by the-design-team, which are shown in-Figure 6. Some-preliminary-calculations were done, at the-same-time, which might-be-required to-substantiate ideas and to-establish approximate-sizes. 


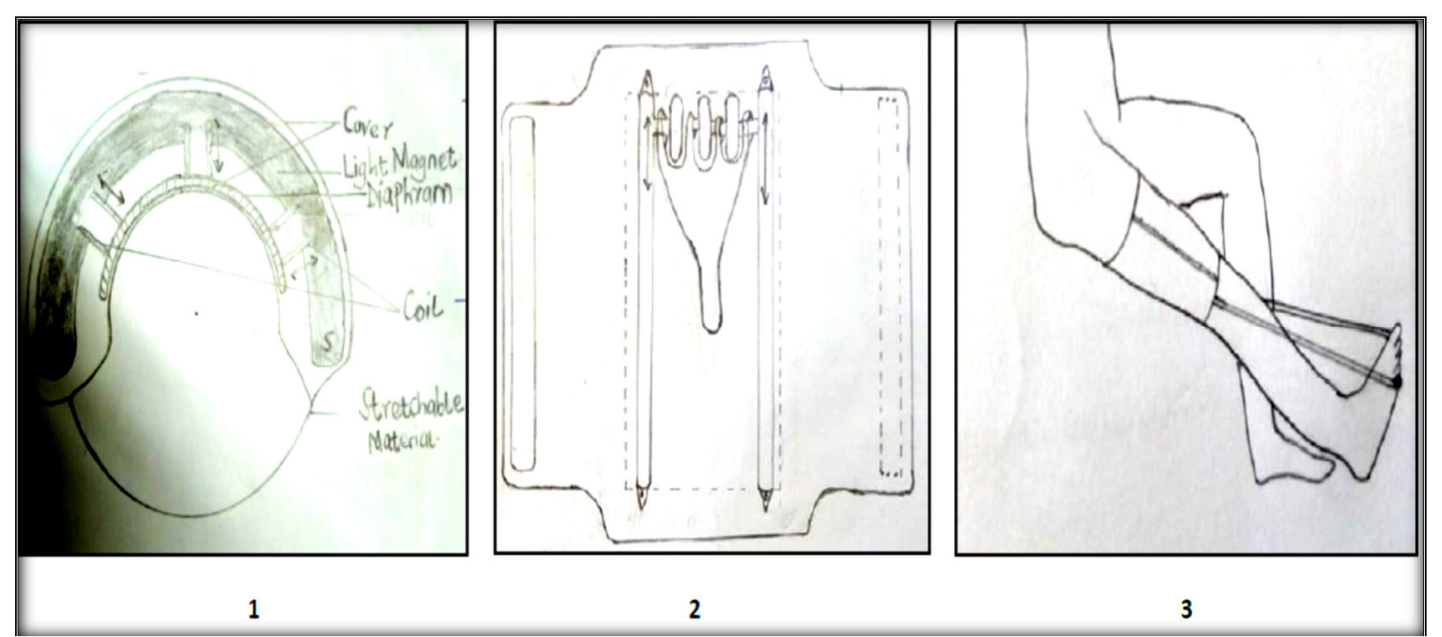

Figure 6: Three design-alternatives.

The-design-alternative (\#1 in Figure 6) is an-electro-mechanical system, it-is to-be-composed of a-coil, alight-magnet, and a-diaphragm, as the-basic-components, with a-stretchable-covering-material. The device can fit both; on the-calf and on the-thigh-muscles. The-electrical-system involves the-supply of Alternating-Current (AC) to the-coil, which is within the-magnetic-field, of the-light-magnet. As the magnet's magnetic-field and theinduced-magnetic-field on the-coil interacts, the-coil moves-inwards, pushing the-diaphragm. This-enables thedevice to-give a-pressing-action, on the-affected-muscle, supposedly relieving the-pain.

The-second-design is made-up of a-wrap-round-piece, on-which massage-wheels are mounted, so-as toenhance the-massaging-action. Mounting gives the-rollers better-massaging, since the-pressure is applied on themuscle the-wrap-round-piece. The-massaging-wheels transverse the-muscle by the-use of a-handle that is attached to the-axle of the-wheels, and the-motion is guided by a-rail. The-interior of the-device is made of a-layer of protrusions, which give a-finger-like-massage, by smoothly-penetrating to the affected-muscle, this with the-wheel massaging-rollers give a-double-action-massage.

The-third-proposed-device will be using primarily a-stretching-function, while massaging is secondary. Theinner-part of the-device will-be-spiked, hence, on stretching it will produce some-close-skin-contact. The-device is to-be adjustable, to-accommodate several-sizes.

\subsection{Selection of the best-design-alternative.}

Alternative design \# 2 was selected, via a-EDWM, with the-highest-score of 0.72 ; while Alternative \# 1 scored 0.63; and Alternative \# 3-- 0.47. Analogous to Starovoytova \& Namango (2016), to-confirm the- choice, additional-method, of selection of best-design-alternative, was used, namely 'D \& R-method'.

\subsection{Preliminary selection of material-groups.}

In-preliminary-selection of material-groups, Engineering-materials are sorted into the-family-groups, such- as: polymers, metals, ceramics, glasses, natural-materials, composites, and hybrids; each of these families/ groups has a-set of attributes (property-profile), which can be plotted in a-material-property-chart (e.g., Ashby-Materials Selection-Charts (see Ashby, 2005).

Besides, according-to Jerz (2014), the-selection of materials goes-through four-steps: translation, screening, ranking, and support-information. Translation-stage involves establishing the-constrains on material-properties and the-process-attributes. The-properties for consideration, in-this-study, were-limited to: (i) technical-properties of materials (e.g., density, conductivity, strength, etc.); (ii) manufacturing of materials (e.g., easy to manufacture with existing-manufacturing-facilities); (iii) economic-properties of materials (availability and cost for material and production); and (iv) ecological-properties of materials (recycle-ability, sustainability, etc.). Besides, materials, which come in-contact-with the-human-skin, should-be carefully-selected; this is due-to some-skin-diseases, suchas Eczema (recurrent-skin inflammation) (Mason, 2009), therefore, the-materials-bio-comparability will be also under-consideration.

Natural-chrome-tanned-leather has excellent-mechanical-properties of bursting, and thermal-resistant properties (Yu, 2013); however it-is expensive, and the-chrome-tanned-leather may not be compatible-with some people's skin, especially those suffering-from the-eczema-disease of the-skin (Mason, 2009). Synthetic-leather is, hence, to-be used, due to its-flexibility, comparability, availability, and price. The handle is to-be-made of wood, due to its-specific-gravity, of which the-general-substance that make it up is 1.5 regardless of the wood-type (Green, 1999). Galvanized-steel-sheets, which do not easily-rust, will be used for rails. 
3.6. Design-target and Anthropometric-measurements, to be used in the-design.

$50^{\text {th }}$ percentile (covering $90 \%$ of the-population) adult-male, was selected, as most-appropriate design targetpopulation. Figure 7 shows the-relevant-anthropometric-dimensions, needed for the-design. InternationalStandards, for Anthropometric-Assessment by Marfell-Jones (2001) and Anthropometrical- data from Fryar (2012), were used, to-obtain one-dimensional-values for these-dimensions.
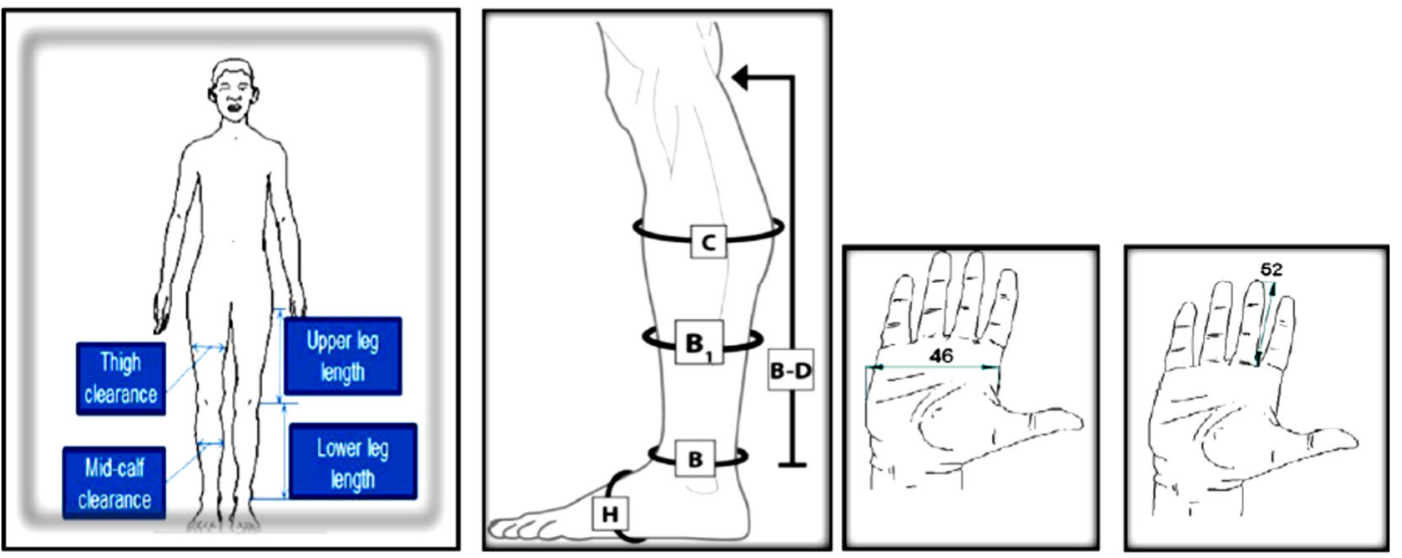

Figure 7: Relevant Anthropometric-dimensions.

Note: Dimensions B and $\mathrm{H}$ were not considered in this-design.

\subsection{Description of the best-design-alternative.}

Fundamentally, fatigue is occurring due-to the-Isometric-Contraction, with the-increasing lactic-acid accumulation. Influence of massage on Muscle-Blood-Volume (MBV) is particularly-important, in this designalternative, since according-to Imai et al. (2016); and Mori et al. (2004), the-effect is thought to help enhanceremoval of metabolic-waste by-products, such-as lactic-acid, thus enhancing recovery from muscle-fatigue. Therotating-roller will give superficial-massage and provide soft-tissue manipulation, towards the-calf-parts, achieving relaxations on-muscle-activity, and consequently improving blood- circulation in the-body.

Figure 8 shows the-ideation-diagram, which is the-general-plan-view of the-proposed-device. The yellow outer-lines represent the-synthetic-leather-part, to-wrap-around the-calf-muscles. It spans for $430 \mathrm{~mm}$, with theflaps, where the-Velcro-strips are attached, so as to-allow adjustment. The-blue-parts are the-rails, on which themassaging wheel-axel is to-move-through. The-part, represented in-green, is the massaging-system, made-up of the-massaging-wheels, the-axel, and the-handle. Lastly, the-part, represented in-pink is the-spiked-area, which surface, gives a-finger-like-massage to the-muscles.

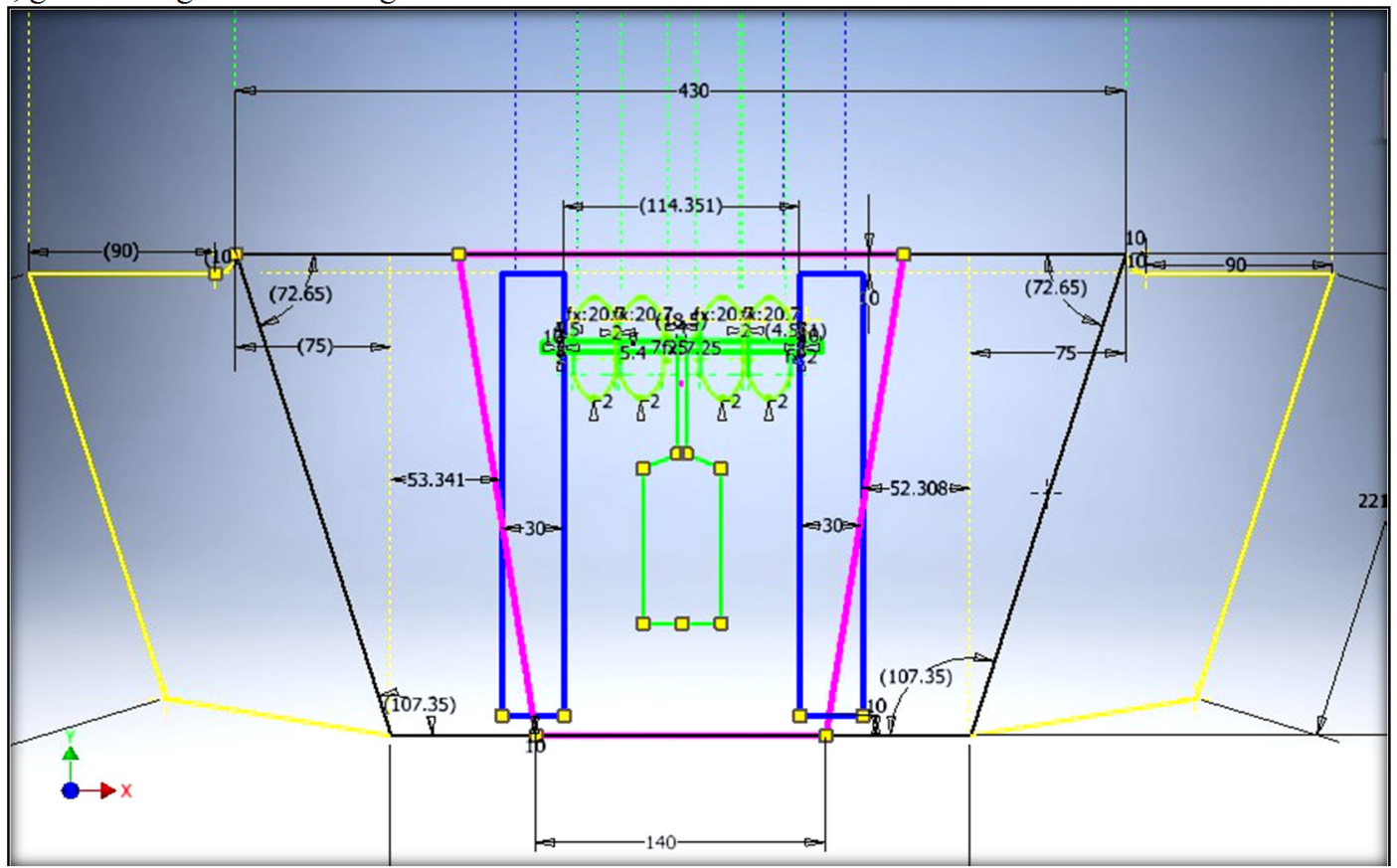

Figure 8: Ideation diagram.

The-height of the-rail should be such, to-allow free-rotation of the-rollers, massage, as-well-as support on 
the-leather-surface by rivets. Positioning of four-Velcro-strips, for adjustability were calculated to be positioned in the-upper-side at 17,21,25, and $29 \mathrm{~cm}$, from the-centre and on both-sides, and at points $10,13,16$, and $19 \mathrm{~cm}$ (on the-lower-side). The-handle-dimensions was calculated, based on the design-target and arm-dimensions, at $25.45 \mathrm{~mm}$, and optimized (for ease of fabrication) to be $30 \mathrm{~mm}$. The-smallest-wheel, available, at the-time of thestudy, was used.

The-layout was analyzed for forces, stresses, etc., and calculations, necessary were made to-be-certain that the-parts can perform satisfactorily. Engineering Design Software -- SolidWorks, 2013 (design and simulation tool) was used.

\subsection{Simulation and Analysis.}

By identifying the-loads, the-governing-failure-modes and tentatively selecting the-appropriate candidate material, the-failure-prediction-scenarios provide a-basis for choosing the optimal-combination of design parameters: geometry, material, and loads (Budynas-Nisbet, 2008). A-key-strategy in the-PDP (Product Development-Process) is to-avert failure of a machine/device/structure, by predicting and analyzing potential-failure-scenarios at thedesign-stage, before it-is built. Factor of safety (FoS), also-known-as (and used-interchangeably-with) safetyfactor (SF), and design-factor of safety $(\mathrm{N})$, is a-term, describing the capacity of a-system, beyond the-expectedloads or actual-loads. According to Starovoytova \& Njoroge (2016): "Essentially, the-factor of safety is howmuch-stronger the-system is than it usually needs to-be for an-intended-load'. Factor-Safety of 4 was chosen, tocarter for changes in-material-properties, due-to normal-use and possible-extreme-weather. The-force of 557 Newton (since it-is the-highest-value for $95^{\text {th }}$ percentile-male), was chosen for the-test (in-accordance with Schutte, 2007), where device ultimate tensile- strength at steady-loading is considered.

Operating-conditions for the-test are shown in Table 1, while Table 2 specifies Reaction-Force and Moment, for Fixed-Constraint 1; and Table 3 details the-summary of results.

Table 1: Operating-conditions.

\begin{tabular}{|l|l|}
\hline Load Type & Force \\
\hline Maanitude & $557.000 \mathrm{~N}$ \\
\hline Vector $X$ & $-17.667 \mathrm{~N}$ \\
\hline Vector $Y$ & $211.753 \mathrm{~N}$ \\
\hline Vector $Z$ & $514.876 \mathrm{~N}$ \\
\hline
\end{tabular}

Table 2: Reaction-Force and Moment, for Fixed-Constraint 1.

\begin{tabular}{|c|c|c|c|c|}
\hline \multirow{2}{*}{ Constraint Name } & \multicolumn{2}{|c|}{ Reaction Force } & \multicolumn{2}{|c|}{ Reaction Moment } \\
\hline & Magnitude & Component $(X, Y, Z)$ & Magnitude & Component $(X, Y, Z)$ \\
\hline \multirow{3}{*}{ Fixed Constraint: 1} & \multirow{3}{*}{$557 \mathrm{~N}$} & $17.6667 \mathrm{~N}$ & \multirow{3}{*}{$45.7263 \mathrm{~N} \mathrm{~m}$} & $45.3359 \mathrm{~N} \mathrm{~m}$ \\
\hline & & $-211.753 N$ & & $4.73968 \mathrm{~N} \mathrm{~m}$ \\
\hline & & $-514.876 N$ & & $-3.61744 \mathrm{~N} \mathrm{~m}$ \\
\hline
\end{tabular}

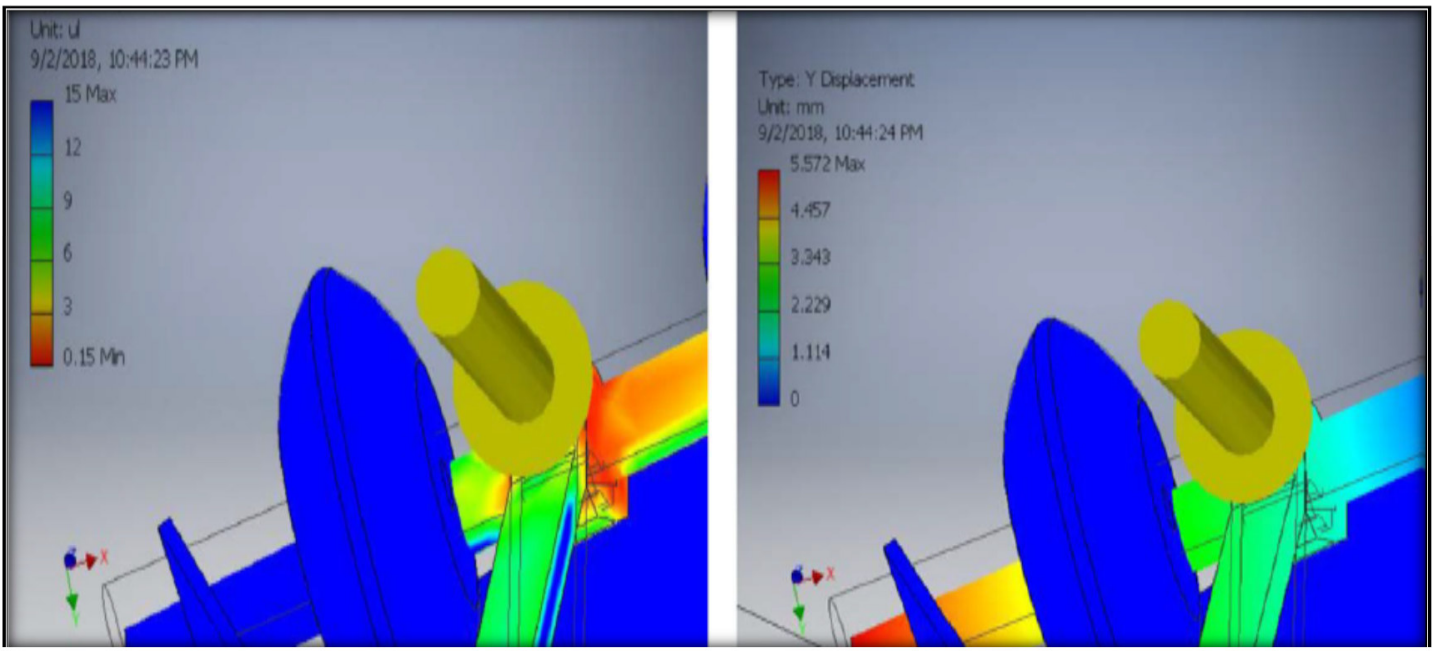

Figure 9: Factor of Safety (left) and Displacement (right) results. 
Table 3: Result Summary.

\begin{tabular}{|c|c|c|}
\hline Name & Minimum & Maximum \\
\hline Valume & \multicolumn{2}{|l|}{$453711 \mathrm{~mm}^{-3}$} \\
\hline Mass & \multicolumn{2}{|l|}{$2.24525 \mathrm{~kg}$} \\
\hline Van Mises Stress & O MPa & $1372.3 \mathrm{MPa}$ \\
\hline 1st Princidal Storess & $-207.62 \mathrm{MPa}$ & $1702.85 \mathrm{MPa}$ \\
\hline 3rd Principal Stress & $-1290.74 \mathrm{MPa}$ & $281.968 \mathrm{MPa}$ \\
\hline Displacement & $0 \mathrm{~mm}$ & | $26.5655 \mathrm{~mm}$ \\
\hline Safety Factor & 0.150842 ul & 15 ul \\
\hline Stress $x \alpha$ & $-635.321 \mathrm{MPa}$ & $667.882 \mathrm{MPa}$ \\
\hline Stress Xr & $-432.627 \mathrm{MPa}$ & $373.347 \mathrm{MPa}$ \\
\hline Stress $x z$ & $-618.778 \mathrm{MPa}$ & $537.83 \mathrm{MPa}$ \\
\hline Stuess $M$ & $-453.349 \mathrm{MPd}$ & $470.41 \mathrm{MPa}$ \\
\hline Stress $r z$ & $-373.512 \mathrm{MPa}$ & $414.638 \mathrm{MPa}$ \\
\hline Stress $Z Z$ & $-965.003 \mathrm{MPa}$ & $1518.52 \mathrm{MPa}$ \\
\hline$X$ Displacement & $-25.8904 \mathrm{~mm}$ & $0.613642 \mathrm{~mm}$ \\
\hline Y Displacement & $-0.268855 \mathrm{~mm}$ & $5.57165 \mathrm{~mm}$ \\
\hline$Z$ Displacement & $-1.08114 \mathrm{~mm}$ & $11.7049 \mathrm{~mm}$ \\
\hline Equivalent strain & o u & 0.0057876 ul \\
\hline 1st Princiad Storain & $\mid-0.000000203956$ ul| & 0.00686072 ul \\
\hline 3rd Principal Strain & -0.00561485 ul & | o ul \\
\hline Strain $x x$ & -0.00215372 ul & $\mid 0.00233776$ ul \\
\hline Strain $\mathrm{xr}$ & -0.00250727 ul & 0.00216372 ul \\
\hline Strain $x z$ & |-0.0035861 ul & $\mid 0.00311697$ ul \\
\hline Strain $\mathrm{rr}$ & -0.00242138 ul & $\mid 0.00171521$ ul \\
\hline Strain $r z$ & -0.00216467 ul & |0.00240301 ul \\
\hline Strain ZZ & -0.00407341 ul & |ul \\
\hline Contact Pressure & O MPa & $2070.52 \mathrm{MPa}$ \\
\hline Cantact Pressure $X$ & $-1926.3 \mathrm{MPa}$ & $1904.793 \mathrm{MPa}$ \\
\hline Cantact Pressure $Y$ & $-208.352 \mathrm{MPa}$ & | $392.925 \mathrm{MPa}$ \\
\hline Contect Pressure $Z$ & $-1550.56 \mathrm{MPd}$ & $802.365 \mathrm{MPa}$ \\
\hline
\end{tabular}

Figure 9 shows a non-uniform-displacement, along the-axel; besides the-Factor of Safety as-low-as $0.15 \mathrm{Mn}$ was reported, which is an-indication that the-axel could eventually fracture. Both-indicators necessitated corrective-measures, taken on the-handle.

Other-results, obtained from the-stress-analysis, include the-von-Misses-stress, the $1^{\text {st }}$ and $3^{\text {rd }}$ Principle-stress and strain, Equivalent-Strain and Contact-pressure.

\subsection{Conceptual Design.}

Conceptual-design of the-massaging-device was optimized, according-to results of simulations, calculations, and fundamental engineering-product-design-principles. Figure 10 shows the-functional-elements/parts of themassaging-device, while Figure 11 shows its-assembly. 

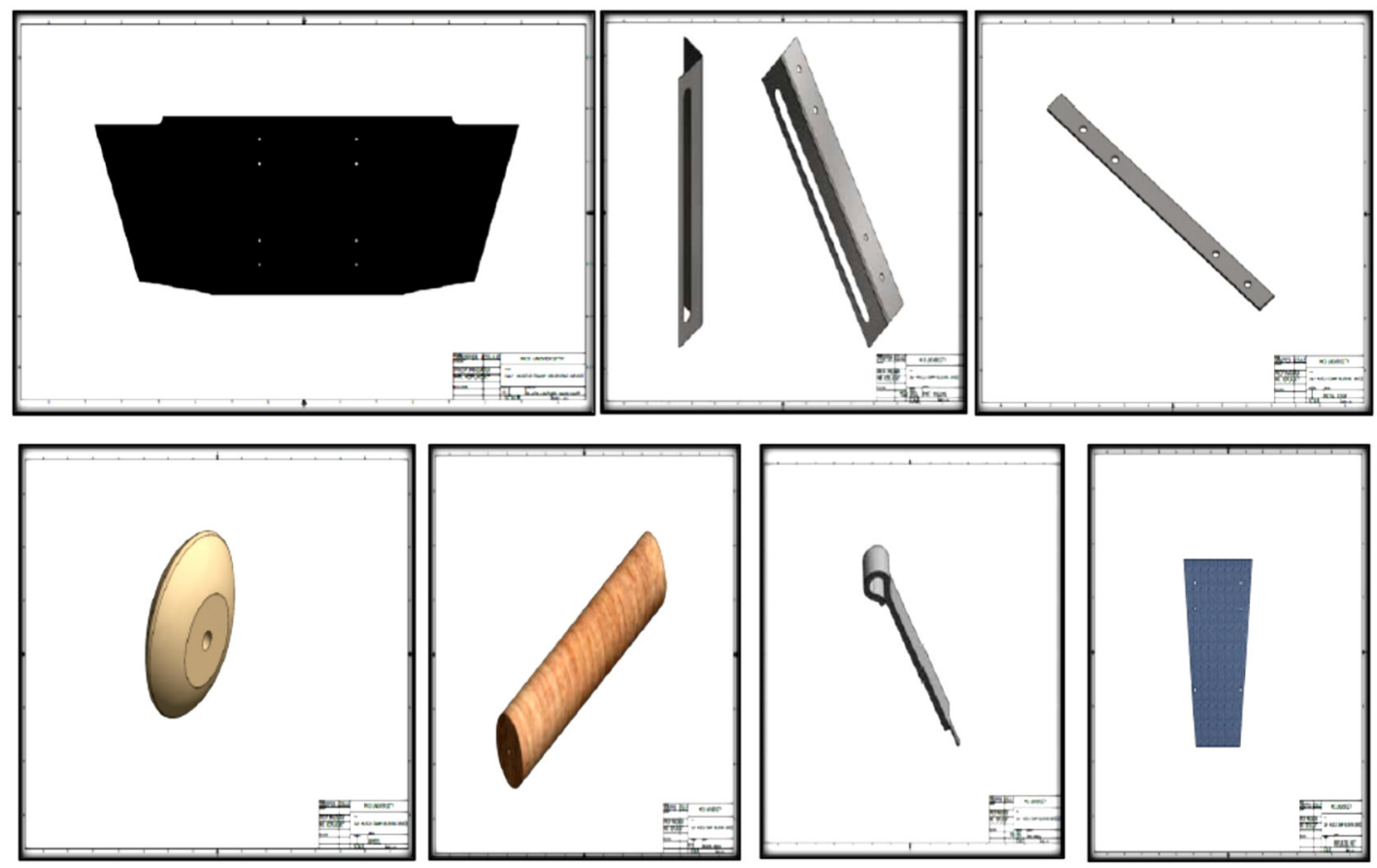

Figure 10: Functional-parts of the-massaging-device.

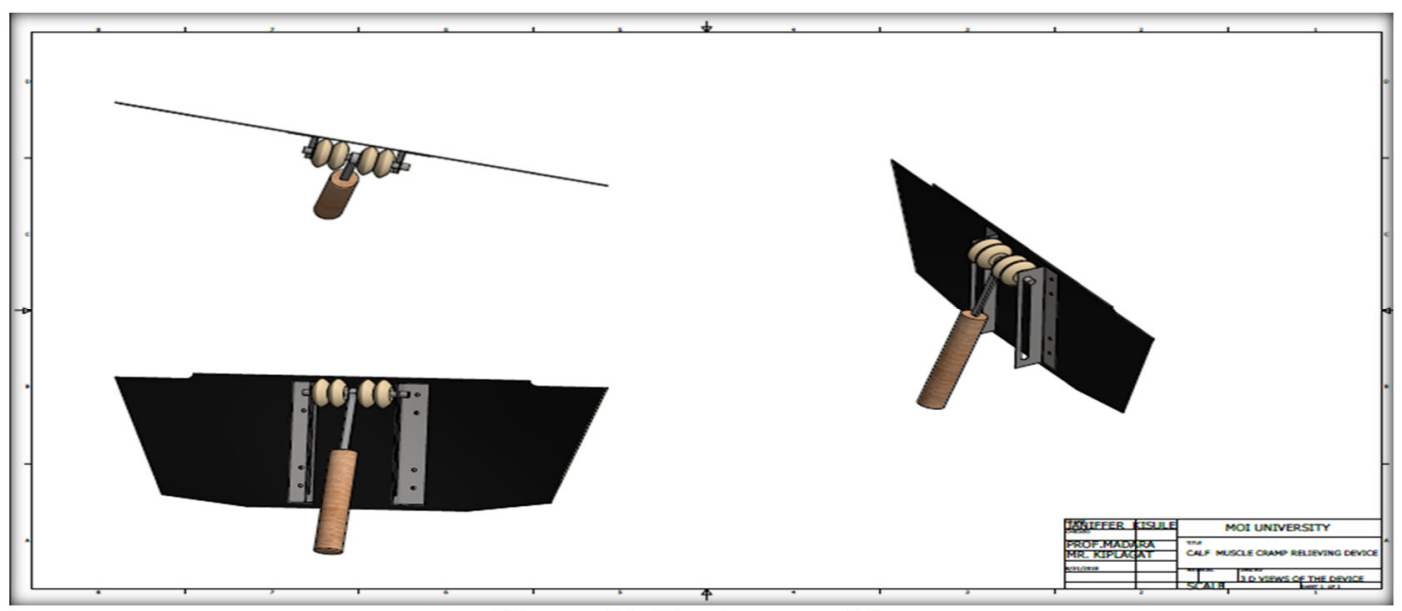

Figure 11: Device-assembly.

\section{Discussion.}

As stated-earlier, the-scope of the-project was-limited-to the-conceptual-design. On the-other-hand, prototyping and testing-stages, if carried-out, can give a-real-picture of the device-functionality. The-author proposes furtherwork on prototyping and testing to-be-carried-out, leading-to detail-design and embodiment-design.

Besides, the-general-contouring, of the-calf-area, of the-leg, is different, length and the-circumference variesgreatly, hence fitting the-wrap-round-piece. For-instance, Figure 12 shows 9 combinations with different-length of leg (short, medium, and long), and varying-calves (small, medium, and big). The-study, hence, recommends further-studies, to-optimize the-dimensions of the-device, to-accommodate different shapes of calf-muscles; and the-use of stretchable-material (and also durable), which can easily take the- shape of the-leg. 


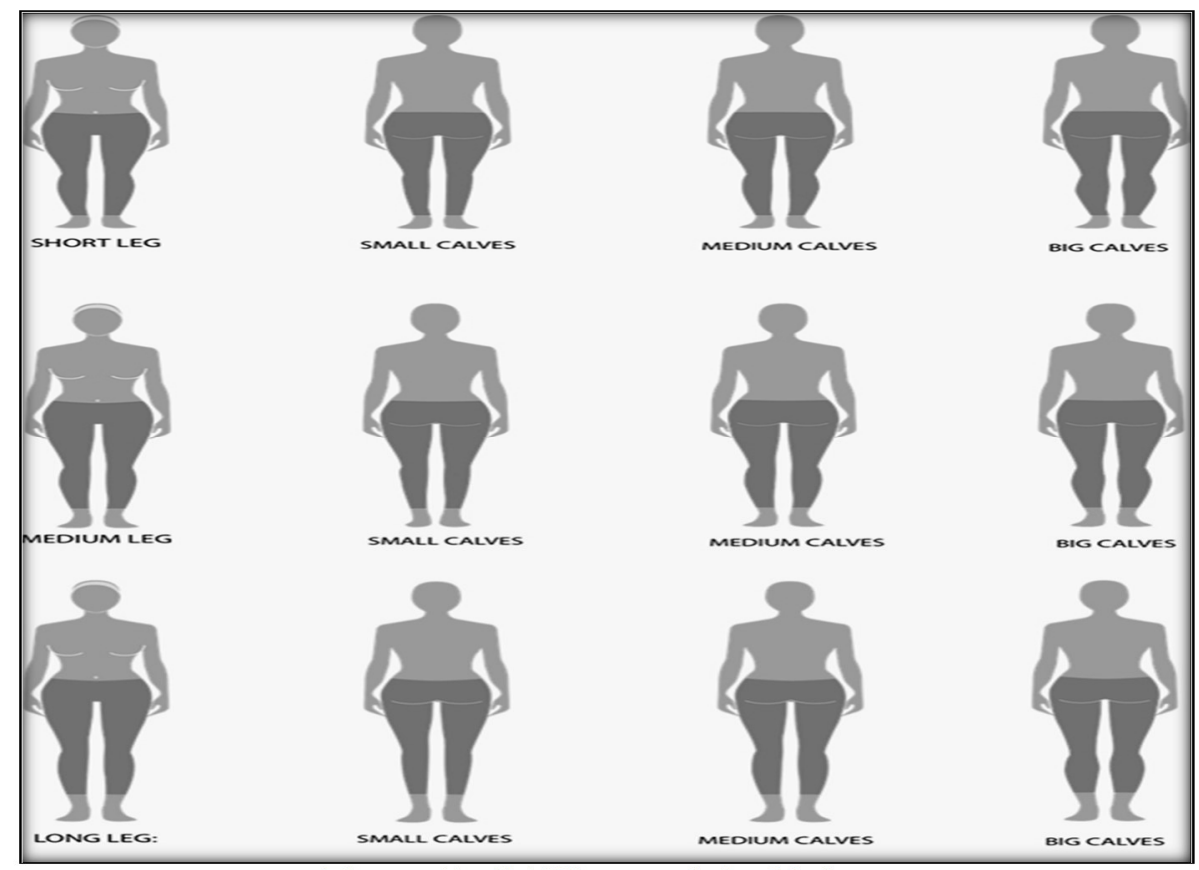

Figure 12: Calf Shape and size Variety.

This-unfunded concise-study was preliminary, by nature; its-results, are largely, relatively-positive, providing a-good-starting-point, for further and much-deeper-study, on the-same. Next-logical-step, would be a-detaileddesign, which can-be-generated, using 3D-solid-modeling CAD-programs, such-as SolidWorks. CAD-models can-be created, for components and assemblies, to-check, for interference, before any-physical parts are made.

Also, the-Finite-Element-Analysis/Method (FEA/FEM) can-be used, to-conduct stress-strain investigations. The-most-characteristic-case is to-use FEA to-understand what stress will-develop, in-a-part, under certainloading-conditions. Besides, AUTODESK Simulation-Mechanical, can-be-used, to-perform Stress-Strainanalyses; the-same-package can-be-also-used to-perform heat-transfer-modeling.

In-addition, final trade-off of performances-test (see Masctelli, 2000), and FMEA-tests should-be conducted, as every-product has some-possible-failure-point, and it-is important to-identify such failure point(s) and thesubsequent-effect(s). Moreover, a-particular-component-failure is often identified, during the-use-ability-testingprocess, meaning that only that-component should-be redesigned, and not the entire product (see Starovoytova, 2018).

The-current (conceptual)-design is rather-uncomplicated, hence, EDWDM was considered to-be sufficient, during selection of best-design-alternative. At a-later (detail design-stage) additional-methods, such-as: PuCC; AHP (Analytic-Hierarchy-Process); and TRIZ (Theory of Inventive-Problem-Solving) should-be-applied (see Renzi et al., 2017; Starovoytova , 2015; Starovoytova et al., 2015; Mansor et al., 2013; 2014).

Moreover, it-is a-standard-procedure to-analyze the-marketing-aspect of any-newly-designed-device, and hence, it-is recommended.

Lastly, reviewing the-British-Standard for Workplace-First-Aid BS8599-1, for Professional-First- Aid-Kits (Sports), it was exposed that there is absolutely-nothing that it provided, for the-relieve of EAMC, under suchstandard. In-particular, according to the-standard, a-Standard-Sports First-Aid-Kit should provide the-treatmentsolutions for the-following-conditions: Bleeding, Asthmatic-attack, Broken-bone, Concussion, Diabetic-attack, Eye-injury, Fractured-bone, Hypothermia, Shock, Soft-tissue injury, and in addition, it should contain a-tweezers and a-paramedic-shears. Taking into-consideration that EAMC is rather-common, in-sports, the-study, therefore, recommends to-include into-first-aid Sport-kit, a-device, which could help in-managing EAMC, such-as for example, the-massaging-device, designed by this-study.

\section{Conclusions and Recommendations.}

The-current-study revealed that the-patho-physiology, causing EAMC, is most-likely multi-factorial and complex.

Besides, this-unfunded concise-study was preliminary, by nature; its-results, are largely, relatively positive, providing a-good-starting-point, for further and much-deeper-study, on the-same. The-study, hence, further recommends:

i) More-advanced-methods, such-as PuCC; AHP, and TRIZ should be considered in-selection of the-best design-alternative;

ii) Further-studies, to-optimize the-dimensions of the-device, to-accommodate differentshapes of calf-muscles; 
iii) To-conduct prototyping and a-detail-design;

iv) Additional-tests, such-as FEA/FEM and the-use-ability-testing should be incorporated;

v) Comprehensive materials-selection should be detailed via Ashby-charts; and

vi) To-analyze the-marketing-aspect of the-final-device.

Lastly, the-author would-like-to-emphasize that there is absolutely-nothing that can ever-be-perfect that is made by man, especially when it-is at its-initial-stages, and, thus, the-author would-like-to-welcome constructive expert-criticism from the-readers (if any).

\section{Acknowledgement.}

The-author particularly appreciates hard-work, done by a-Research-Assistant, MIT, SOE, MU -- Janiffer Mueni Kisule, during design-phase, of the-study.

\section{References}

Allen, K. and Carlson-Skalak, S. (1998). "Defining Product Architecture in Conceptual Design", ASME Design Engineering Technical Conference, ASME, Atlanta, Georgia, USA.

Allen, J. and Mistree, F. (1997). "Decision-Based Design: Where Should We Go from Here?" Notes of 1997 decision-based design workshop.

Angus, S. (2001). "Massage therapy for sprinters and runners", Clin Podiatr Med Surg.; 18.

Armstrong, S. and Cross, T. (2013).”Exercise associated muscle cramps”, Medicine Today, 14(11).

Armstrong, L. and Maresh, C. (1993). "The exertional heat illness: a risk of athletic participation", Med Exerc Nutr Health; 2.

Armstrong, R.; Warren, G. and Warren, J. (1991). "Mechanisms of exercise induced muscle fibre injury", Sports Med.; 12.

Arya, C. (2009). Design of Structural Elements. Third Edition: Concrete, steelwork, masonry and timber designs to British Standards and Eurocodes. Taylor \& Francis 2 Park Square, Milton Park, Abingdon, Oxon.

Ashby, M. (1999). Materials selection in mechanical design. Butterworth-Heinemann, Oxford, Second edition.

Ashby, M. (2005). Materials Selection in Mechanical Design, 3rd Ed. Butterworth-Heinemann, Oxford, UK.

Ashby. (2004). Material Selection in Mechanical Design.

Bailey, J. (2011). Practical Living For Everyday with MS. Muscle Spasms and Stiffness. Ireland: The Multiple Sclerosis Society of Ireland.

Behm, D.; Peach, A.; Maddigan, M.; Aboodarda, S.; DiSanto, M.; Button, D.; et al. (2013). "Massage and stretching reduce spinal reflex excitability without affecting twitch contractile properties", $J$ Electromyogr Kinesiol; 23.

Belton, V. and Stewart, T. (2002). Multiple Criteria Decision Analysis: An Integrated Approach. Boston: Kluwer Academic.

Bentley, S. (1996). "Exercise-induced muscle cramp: Proposed mechanisms and management", Sports Med.; 21.

Bergeron, M. (2003). "Heat cramps: fluid and electrolyte challenges during tennis in the heat", J. Sci. Med. Sport, 6.

Bergeron, M. (2008). “Muscle cramps during exercise -- Is it fatigue or electrolyte deficit?”, Curr Sports Med rep.; 7.

Bergeron, M. (1996). "Heat cramps during tennis: a case report", Int. J. Sport Nutr., 6.

Bergeron, M. (2007). "Exertional heat cramps: recovery and return to play”, J. Sport Rehabil., 16.

BMJ (2014). Publishing Group Limited: Patient information from the BMJ Group. Leg cramps.

Braulick, K.; Miller, K.; Albrecht, J.; Tucker, J. and Deal, J. (2013). "Significant and serious dehydration does not affect skeletal muscle cramp threshold frequency", Br J Sports Med; 47.

Brick. (2017, October 24). Tim Tam Power Massager 1.5. [Online] Available: www.therxreveiw.com.

(26 August, 2018).

British-Standard for Workplace-First-Aid BS8599-1 (2013). Health \& Safety (First Aid) Regulations: Professional First Aid Kits (Sports).

Brubaker, D.; Whitesel, J. and Barth, B. (1985). "Quinine sulfate: a treatment for recurrent muscle spasms", Athl Train (Greenville, NC), 20.

Budynas-Nisbet, F. (2008). Shigley's Mechanical Engineering Design. (8th edition); McGraw-Hill's. ISBN 0-39076487-6.

Buono, M.; Ball, K. and Kolkhorst, F. (2007). "Sodium ion concentration vs. sweat rate relationship in humans", J. Appl. Physiol., 103.

Burdekin, F. (2007). "General principles of the use of safety factors in design and assessment", Engineering

Failure Analysis, 42.

Byrne, C.; Eston, R.; Edwards, R. (2001). "Characteristics of isometric and dynamic strength loss following eccentric exercise-induced muscle damage", Scand J Med Sci Sports.; 11. 
Callaghan, M. (1993). "The Role of Massage in the Management of the Athlete: A Review", British Journal of Sports Medicine, 27(1).

Chen, W.; Hoyle, C. and Wassenaar, H. (2013). Decision-Based Design: Integrating Consumer Preferences into Engineering Design. London: Springer-Verlag.

Cleary, M.; Ruiz, D.; Eberman, L.; Mitchell, I. and Binkley, H. (2007). "Dehydration, cramping, and exertional rhabdomyolysis: a case report with suggestions for recovery”, J. Sport Rehabil., 16.

Coppin, R.; Wicke, D. and Little, P. (2005). "Managing nocturnal leg cramps: Calf stretching exercises and cessation of quinine treatment", Br J Gen Pract., 55.

Crespi, V.; Galstyan, A. and Lerman, K. (2011). Top-Down vs Bottom-up Methodologies in Multi-Agent System Design, Department of Computer Science, California State University, Los Angeles and USC Information Sciences Institute Autonomous Robots.

D403076 S (1998). By York.

Derrick, E. (1934). "Heat cramps and uraemic cramps, with special reference to their-treatment with sodium chloride", Med J Aust; 2.

Drew, N. (2006). Exercise-associated muscle cramping (EAMC) in Ironman tri-athletes [dissertation]. Cape Town: University of Cape Town.

Edsall, D. (1908). "New disorder from heat: a disorder due to exposure to intense heat", J Am Med Assoc.; 11.

Ernawati, P. (2015). "Evaluating alternatives in product design: A multi criteria group decision approach", International Journal of Services and Operations Management., 18.

Edouard, P. (2014). "Exercise associated muscle cramps: Discussion on causes, prevention and treatment", Science \& Sports, 29.

Eichner, E. (2007). "The role of sodium in 'heat cramping”, Sports Med; 37.

Filippo, A. (2012): The IDEA Conceptual Design Process, PhD thesis, Ryerson University Ryerson University Press.

Friden, J. and Lieber, R. (2001). "Eccentric exercise-induced injuries to contractile and cytoskeletal muscle fibre components", Acta Physiol Scand., 171.

Fryar, C. (2012). Anthropometric reference data for Children and Adults: United States, 2007- 2010. Hyattsville: U.S. Department of Health and Human Services.

Galloway, S. (1999). "Dehydration, rehydration, and exercise in the heat: rehydration strategies for athletic competition", Can J Appl Physiol, 24.

Grainge, B. (2016). Customer reviews: Revive Lights Theraphy Dpl Flex Pad.

Green, J. (1999). Mechanical Properties of Wood. Madison, WI: U.S. Department of Agriculture, Forest Service.

Guissard, N.; Duchateau, J. and Hainaut, K. (1988). "Muscle stretching and motoneuron excitability",

Eur J Appl Physiol Occup Physiol.; 58.

Halperin, I.; Aboodarda, S.; Button, D.; Andersen, L. and Behm, D. (2014). "Roller Massager Improves

Range of Motion of Plantar Flexor Muscles without Subsequent Decreases in Force Parameters", International Journal of Sports Physical Therapy, 9(1).

Hemmings, B.; et al. (2000). "Effects of massage on physiological restoration, perceived recovery and repeated sports performance", J Sports Medicine, 34.

Hilbert, A.; et al. (2003). "Effects of massage on delayed-onset muscle soreness", Br J Sports Medicine; 37.

Hutton, R. and Nelson, L. (1986). "Stretch sensitivity of Golgi tendon organs in fatigued gastrocnemius muscle", Med Sci Sports Exerc, 18.

Imai, N.; Ito, T.; Suda, K.; Miyasaka, D. and Endo, N. (2016). "Manual Calf Massage and Passive Ankle Motion Decrease the Risk of Vein Thromboembolism after Total Hip Arthroplasty".

Jahic, D. and Begic, E. (2018). "Exercise-Associated Muscle Cramp-Doubts About the Cause", Mater Sociomed., 30(1). DOI: $10.5455 / \mathrm{msm} .2018 .30 .67-69$.

Jangager, J. (2005). User considerations in early stages of product development - theories and methods. Department of Machine Design, Royal Institute of Technology, Stockholm. Dissertation (PhD).

Jerz, J. (2014). Selection of engineering materials and advanced technologies for specific industrial application. ReasearchGate.

Jönhagen, S.; Ackermann, P.; Eriksson, T.; Saartok, T. and Renström, A. (2004). "Sports Massage after Eccentric Exercise", The American Journal of Sports Medicine, 32(6).

Jung, A.; Bishop, P.; Al-Nawwas, A. and Dale, R. (2005). "Influence of hydration and electrolyte supplementation on incidence and time to onset of exercise associated muscle cramps", J Athl Train; 40.

Juvinall, R. and Marshek, K. (2012). Fundamentals of Machine Component Design. Wiley. 5th ed.

Kantorowski, P.; Hilter, W.; Garrett, W.; Douglas, P.; Smith, R. and O’Toole, M. (1990). "Cramping studies in 2600 endurance athletes", Med Sci Sports Exerc; 22.

Kamat, R.; Halwanie, A.; Fukumi, M. and ITO, T. (2017). "Design a Manual Calf Massager for Prolonged Standing Workers by Using Ergonomic Approach”, 日本機械学会第27 回設計工学 システム部門講演 
会 講演論文集, [2017.9.13-15].

Kargus, A. (2009). "Muscle Cramps: Causes and Treatment Options", The Journal of the American Chiropratric Association, 2.

Kenefick, R.; Maresh, G.; Armstrong, L.; et al. (2000). "Plasma vasopressin and aldosterone responses to oral and intravenous saline rehydration", J. Appl. Physiol., 89.

Khandani, S. (2005). [Online] Available: www.iisme.org/ETPExemplary.cfm. (26 August, 2018).

Krishnamurty, S. (2006). "Normative Decision Analysis in Engineering Design", Decision Making in Engineering Design, 4 (4).

Ladell, W. and Camb, M. (1949). "Heat cramps", The Lancet, 254.

Ladell, W. (1949). "Heat cramps", Lancet; 2.

Layzer, R. (1994). "The origin of muscle fasciculations and cramps", Muscle Nerve, 17.

Lee, H.; Wu, S. AND You, J. (2009). "Quantitative application of transverse friction massage and its neurological effects on flexor carpiradialis", Man Ther; 14.

Love, T. (2003). Customers' Use of Products as Design Tools. Proceedings of the 6th Asian design international conference. Journal of the Asian design international conference. Tsukuba: Institute of Art and Design, University of Tsukuba.

Manjra, S. (1991). Muscle Cramps in Athletes [bachelor's honors thesis]. Cape Town, S. Africa: University of Cape Town; 1991.

Manjra, S.; Schwellnus, M. and Noakes, T. (1996). "Risk factors for exercise associated muscle cramping (EAMC) in marathon runners", Med Sci Sports Exerc; 28(5): S167.

Mansor, M.; Sapuan, E.; Zainudin, A.; et al. (2013). "Hybrid Natural and Glass Fibers Reinforced Polymer Composites Material Selection Using Analytical Hierarchy Process for Automotive Brake Lever Design", Materials and Design, 51.

Mansor, M.; Sapuan, E.; Zainudin, A. ; et al. (2014). "Conceptual Design of Kenaf Fiber Polymer Composite Automotive Parking Brake Lever Using Integrated TRIZ-Morphological Chart Analytic Hierarchy Process Method", Materials and Design, 54.

Maquirriain, J. and Merello, M. (2007). "The athlete with muscular cramps: clinical approach", J Am Acad Orthop Surg., 15.

Mascitelli, R. (2000). "From Experience: Harnessing Tacit Knowledge to Achieve Breakthrough Innovation", Journal Product Innovation Management, Pg.170-193.

Mathews, P. (2016). Buy Yosoo Calf Brace AdustbleShin Splint.

Matt. (2018). Tim Tam Power Massager V1.5.

Maughan, R. (1986). "Exercise induced muscle cramp: a prospective biochemical study in marathon runners", $J$ Sports Sci.; 4.

Marfell-Jones, M. (2001). International Standards for Anthropometric Assessment. Palmerston North: International Society for the Advancement of Kin-anthropometry.

McCance, R. (1936a). “Experimental sodium chloride deficiency in man”, Proc R Soc Lond B; 119.

McCance, R. (1936b). "Sodium deficiencies in clinical medicine", Lancet, 1.

Miller, K. and Knight, K. (2007). "Pain and soreness associated with a percutaneous electrical stimulation muscle cramping protocol", Muscle Nerve.; 36.

Miller, K. and Knight, K. (2009). "Electrical stimulation cramp threshold frequency correlates well with the occurrence of skeletal muscle cramps", Muscle Nerve; 39.

Miller, K. (2014). "Electrolyte and plasma responses after pickle juice, mustard, and deionized water ingestion in dehydrated humans", J Athl Train, 49.

Miller, K. (2015). "Rethinking the Cause of Exercise-Associated Muscle Cramping: Moving beyond Dehydration and Electrolyte Losses", Curr Sports Med Rep, 14.

Miller, K.; Stone, M.; Huxel, K. and Edwards, J. (2010). "Exercise associated muscle cramps: causes, treatment, and prevention", Sports Health; 2.

Miller, T. and Layzer, R. (2005). "Muscle cramps", Muscle Nerve, 32.

Mori, H.; Ohsawa, H.; Tanaka, T.; et al. (2004). "Effect of Massage on Blood Flow and Muscle Fatigue Following Isometric Lumbar Exercise", Med Sci Monit, 10.

Moss, K. (1923). "Some effects of high air temperatures and muscular exertion upon colliers", Proc R Soc Lond B Biol Sci.; 95.

Mustafa, A.; Abdollah, M.; Ismail, H.; et al. (2014). "Materials Selection for eco-Aware Lightweight Friction Material", Mechanics and Industry, 15 (4).

Nelson, N. and Churilla, M. (2016). "A Narrative Review of Exercise-Associated Muscle Cramps: Factors That Contribute To Neuromuscular Fatigue And Management Implications", Muscle \& Nerve, 2016.

Nelson, L. and Hutton, R. (1986). "Dynamic and static stretch response in muscle spindle receptors in fatigued muscle”, Med Sci Sports Exerc; 18. 
O’Connell, K.; Posthumus, M.; Schwellnus, M. and Collins, M. (2013). "Collagen genes and exercise associated muscle cramping", Clin J Sport Med; 23.

Oswald, R. (1925). "Saline drink in industrial fatigue", Lancet; 1.

Parisi, L.; Pierelli, F.; Amabile, G.; et al. (2003). "Muscular cramps: proposals for a new classification", Acta Neurol Scand; 107.

Pidcock, R. M. (2005). Patent No. 6027434. United States of America.

Pugh, S. (1981). Concept selection: a method that works. In: Hubka, V. (ed.), Review of design methodology. Proceedings international conference on engineering design, March 1981, Rome. Zürich: Heurista.

Qiu, J. and Kang, J. (2017). "Exercise Associated Muscle Cramps - A Current Perspective", Scientific Pages Sports Med, 1(1).

Rajan, V. (1996). A Framework for Concurrent Assembly Design and Planning. In Proceedings of the First Annual International Conference on Industrial Engineering: Applications and Practice, Houston, TX, December 4-7, 1996.

Rehrer, N.; Smets, A.; Reynaert, H.; et al. (2001). "Effect of exercise on portal vein blood flow in man", Med Sci Sports Exerc, 33.

Renzi, C.; Leali, F. and Di Angelo, L. (2017). "A review on decision-making methods in engineering design for the automotive industry", Journal of Engineering Design, 28 (2).

Riley, J. and Antony, S. (1995). "Leg cramps: differential diagnosis and Management", Am. Fam. Physician, 52.

Robertson, W (2004). "Effects of leg massage on recovery from high intensity cycling exercise", Br J Sports Medicine; 38 (2).

Romer, A.; Weibhahn, G. and Hacker, W. (2001). "Effort-saving product representations in design -results of a questionnaire survey", Design Studies, 22.

Roeleveld, K.; van Engelen, B. and Stegeman, D. (2000). "Possible mechanisms of muscle cramp from temporal and spatial surface EMG characteristics", J. Appl. Physiol., 88.

Roozenburg, N. and Eekels, J. (1995). Product Design, Fundamentals and Methods. Wiley, Chichester, UK.

Rosenhead, J. and Mingers, J. (2001). Rational Analysis for a Problematic World Revisited. Chichester: Wiley.

Ruff, R. (1996). "Effects of length changes on $\mathrm{Na}+$ current amplitude and excitability near and far from the endplate", Muscle Nerve, 19.

Schutte, P.; James, J. and Dias, B. (2007). Ergonomics programmes and standards for functional work capacity. Report number: CSIR/NRE/MIN/ER/2007/ 0121/A. Antrop data

Schwellnus, M.; Nicol, J.; Laubscher, R. and Noakes, T. (2007). "Serum electrolyte concentrations and hydration status are not associated with exercise associated muscle cramping (EAMC) in distance runners", Br J Sports Med., 38.

Schwellnus, M.; Derman, E. and Noakes, T. (1997). “Aetiology of skeletal muscle 'cramps' during exercise: a novel hypothesis", J Sports Sci.; 15.

Schwellnus, M. (2009). "Cause of exercise associated muscle cramps (EAMC) -- altered neuromuscular control, dehydration or electrolyte depletion?", Br J Sports Med; 43.

Schwellnus, M.; Nicol, J.; Laubscher, R. and Noakes, T. (2004). "Serum electrolyte concentration and hydration status are not associated with exercise associated muscle cramping (EAMC) in distance runners", Br J Sports Med; 38

Schwellnus, M.; Drew, N. and Collins, M. (2008). "Muscle cramping in athletes - risk factors, clinical assessment and management", Clin Sports Med; 1.

Schwellnus, M. (2007). "Muscle cramping in the marathon: aetiology and risk Factors", Sports Med., 37.

Schwellnus, M.; Drew, N. and Collins, M. (2011). "Increased running speed and previous cramps rather than dehydration or serum sodium changes predict exercise-associated muscle cramping: a prospective cohort study in 210 Ironman triathletes", Br J Sports Med, 45.

Sefton, J.; Yarar, C. and Berry, J. (2012). "Massage therapy produce short-term improvement in balance, neurological, and cardiovascular measures in older persons", Int J TherMassage Bodywork Res Educ Pract; 5.

Sjogaard, G.; Adams, R. and Saltin, B. (1985). "Water and ion shifts in skeletal muscle of humans with intense dynamic knee extension", Am J Physiol, 248.

Starovoytova, D. and Namango, S. (2016). "Innovative Conceptual Design of Manual-Concrete Block-MakingMachine", Innovative Systems Design and Engineering; ISSN 2222-1727 (Paper) ISSN 2222-2871 (Online), Vol.7, No.7, 2016.

Starovoytova, D. and Njoroge, M. (2016).” Design Simulation and Analysis of Manual Block-Making Machine", Innovative Systems Design and Engineering; ISSN 2222-1727 (Paper) ISSN 2222-2871 (Online), Vol.7, No.7, 2016.

Starovoytova, D. (2018). "Snoring and its Management (Part 2/2): Preliminary Design and Prototyping of AntiSnoring Chin Strap Device”, Innovative Systems Design and Engineering, ISSN 2222-1727 (Paper) ISSN 


\section{2-2871 (Online), Vol.9, No.2.}

Starovoytova, D. (2015). "Theory of inventive problem solving (TRIZ): his-story", IJISET - INTERNATIONAL, Journal of Innovative Science, Engineering \& Technology(U.S.A.), Vol. 2 Issue 7, July 2015, ISSN 2348 7968.

Starovoytova, D. et al. (2015). "Potential of Theory of Innovative Problem Solution (TRIZ) in Engineering Curricula”, IJISET - INTERNATIONAL Journal of Innovative Science, Engineering \& Technology, Vol. 2 Issue 5, May 2015, pp.984-994, ISSN 2348 - 7968.

Stofan, J.; Zachwieja, J.; Horswill, C.; et al. (2005). "Sweat and sodium losses in NCAA football players: a precursor to heat cramps?", Int. J. Sport Nutr. Exerc. Metab., 15.

Stone, M.; Edwards, J.; Stemmans, C.; Ingersoll, C.; Palmieri, R. and Krause, B. (2003). “Certified athletic trainers' perceptions of exercise-associated muscle cramps", J Sport Rehabil., 12.

Sulzer, N.; Schwellnus, M. and Noakes, T. (2005). "Serum electrolytes in Ironman triathletes with exerciseassociated muscle cramping”, Med Sci Sports Exerc; 37.

Summers, K.; Snodgrass, S. and Callister, R. (2013). "Predictors of calf cramping in rugby league", J Strength Cond Res, 1.

Talbot, H. (1935). "Heat cramps", Med.; 14.

Tarnopolsky, M. (2002). "Metabolic myopathies and physical activity: When fatigue is more than simple exertion”, Phys Sports med., 30.

Thomson, D.; Gupta, A.; Arundell, J. and Crosbie, J. (2015). "Deep Soft-Tissue Massage Applied to Healthy Calf Muscle Has No Effect on Passive Mechanical Properties: A Randomized, Single-Blind, Cross-over Study", BMC Sports Science, Medicine and Rehabilitation, 7(1).

Timings.B. (2000). Manufacturing technology. 2nd edition. Butterworth-Heinemann, USA.

Timothy, M. (2005). Muscle Cramps. Wiley Periodicals, Inc.

Ulrich, K. and Eppinger, E. (2008). Product Design and Development, 4th ed. Singapore: Irwin McGraw-Hill.

US 7223251 B1 (2007). By Phillips.

US 6027434 (2005). By Pidcock.

US 6784127B1 (2004). By Yamakawa et al.

US 6645089B2 (2003). By Tsunoda et al.

US6638184B2 (2003). By Nesbitt et al.

US 6499485 B1(2002). By Pepera.

US 6474742 (2002). By Robinson, E.

US 6241696 B1(2001). By York.

US 6210304 B1 (2001). By Scatterday.

US 6146343A (2000). By Steward.

US 6027434 (2000). By Gibbons.

US 6093159A (2000). By Racoosin.

US5868689A (1999). By Faroku et al.

Venable, S. (2009). Drugs Affecting Muscle Spasm and Spasticity. In D. S. Aschenbrenner, Drug Therapy in Nursing; Lippincott Williams \& Wilkins.

Weller, E.; Bachert, P.; Meinck, H.; et al. (1998). "Lack of effect of oral Mg supplementation on Mg in serum, blood cells, and calf muscle", Med. Sci. Sport Exer., 30.

Young, G. (2006). "Leg cramps", Clinical Evidence, 15.

Yu, W. (2013). The Mechanical Properties Of Leather In Relation To Its Softness. East Eisenhower Parkway: ProQues.

Zainuddin, A.; et al. (2005). "Effects of massage on delayed-onset muscle soreness, swelling and recovery of muscle function", J Ath Train; 40(3). 